\title{
Poverty alleviation strategies under informality: evidence for Latin America
}

Martin Caruso Bloeck ${ }^{1 *}$, Sebastian Galiani ${ }^{2}$ and Federico Weinschelbaum ${ }^{3}$

*Correspondence:

martin_

carusobloeck@berkeley.edu

${ }^{1}$ Department of Economics,

University of California,

Berkeley, Berkeley, USA

Full list of author information

is available at the end of the

article

\begin{abstract}
Strategies based on growth and inequality reduction require a long-run horizon, and this paper therefore argues that those strategies need to be complemented by poverty alleviation programs. With regards to such programs, informality in Latin America and the Caribbean is a primary obstacle to carry out means testing income-support programs, and countries in the region have therefore mostly relied on proxy means testing mechanisms. This paper studies the relative effectiveness of these and other mechanisms by way of a formal model in which workers choose between job opportunities in the formal and informal sectors. Although the means testing mechanism allows for a more pro-poor design of transfers, it distorts labor decisions made by workers. On the other hand, (exogenous) proxy means testing does not cause distortions, but its propoor quality is constrained by the power of observable characteristics to infer income levels. However, since taxation is necessary to fund programs, redistribution becomes less effective, especially for programs other than means testing. The paper concludes by discussing the implications of these results for the design of more efficient targeting programs.
\end{abstract}

Keywords: Poverty, Inequality, Means testing, Proxy means testing, Latin America and the Caribbean

JEL Classification: J38, 138

\section{Introduction}

For several decades, poverty has been on a steady downward path, both worldwide and in Latin America and the Caribbean (LAC). Growth in incomes and a decline in inequality in the 2000s have triggered these improvements. Still, there is room for progress, and poverty reduction remains a top priority for societies and policymakers in the LAC region. This paper is therefore dedicated to assessing the effectiveness of poverty reduction strategies.

In terms of poverty, LAC has consistently ranked in the middle of the remaining regions of the world, below Europe and Central Asia and the Middle East and Northern Africa, but above South Asia, East Asia and the Pacific, and sub-Saharan Africa. With the exception of this last region, all regions have gone through a sustained process of poverty reduction. The fall in poverty in LAC has been underpinned by long-run growth in the region, although there has been frequent macroeconomic instability. Inequality

(c) The Author(s) 2019. This article is distributed under the terms of the Creative Commons Attribution 4.0 International License (http://creativecommons.org/licenses/by/4.0/), which permits unrestricted use, distribution, and reproduction in any medium, provided you give appropriate credit to the original author(s) and the source, provide a link to the Creative Commons license, and indicate if changes were made. 
generally rose in the 1990s, while it has fallen in the 2000s. With some exceptions, the gains in the 2000s have more often offset the declines in the 1990s, implying that declines in inequality have contributed to declines in poverty.

This paper estimates the contribution of growth and inequality toward poverty reduction by means of regression-based decompositions, finding that growth has been the main driver behind falling poverty in LAC. This is not because declining inequality is ineffective at reducing poverty-far from it, the estimates indicate that the elasticity of poverty with respect to inequality is rather large, especially in the region. The reason is rather that inequality has not fallen consistently from its values at the beginning of the sample.

That being said, growth and sustained declines in inequality are necessarily long-term strategies for poverty reduction. Even when growth and declines in inequality are sustained, this paper argues that there is a need to complement these developments with poverty alleviation programs. This is because improvements do not automatically spill over to everyone, and groups without the proper human capital and access to better opportunities are unlikely to be able to gain their share of these benefits.

The effectiveness of poverty alleviation programs depends crucially on whether they can efficiently target the poorest sector of the population. High-income countries have mainly relied on means testing strategies to gauge this efficiently, but this requires being able to verify whether incomes have been reported accurately. In a context with huge levels of informality, as is the case in LAC, incomes are generally unobservable to program administrators. As a result, developing countries have adopted proxy means testing mechanisms to assess the poverty status of potential beneficiaries.

This paper compares the performance of these and other alternative mechanisms by means of a formal model. While means testing may steer workers away from more productive opportunities in the informal sector, it allows for a more flexible design of transfers and a greater pro-poor character for a program. On the other hand, proxy means testing generates no distortions in workers' decisions, but the overall pro-poor nature of the program is constrained by the ability of observable characteristics to accurately predict poverty levels. Additionally, since means testing programs do not provide income support for informal workers, the effect of complementing means testing with transfers to informal workers is analyzed. When transfers are granted to all informal workers, the level of filtration to the non-poor is possibly large, while it is not possible to provide greater transfers to the poorest informal workers. As a result, indiscriminate transfers to informal workers are a rather inefficient way to reduce the incidence and depth of poverty. Transfers to informal workers assigned through proxy means testing generate distortions in labor market decisions, a result that contrasts with the effect of proxy means testing alone.

Finally, this paper considers how the design of redistributive programs affects the budget constraints of the public sector. Informality diminishes public revenues for a given tax rate or requires a higher rate for a desired revenue level. Additionally, it makes taxation of the non-poor and targeting of the poor less efficient, weakening the overall distributive effect of public programs. These effects are stronger if income support is provided to informal workers, even by means of proxy means testing. In view of this, this paper argues that greater reliance on means testing may be suitable in LAC. The main reasons are that means testing is a more pro-poor design, curbs the size of the informal 
sector and the losses in revenues associated with it, and avoids unnecessary filtration to the non-poor.

The next section of this paper discusses methodological issues behind the measurement of poverty and presents the evidence on poverty in LAC and the rest of the world. Section 3 studies the role of growth and inequality in poverty reduction and estimates the elasticities of poverty with respect to growth and inequality. It also quantifies the contribution of each of these factors to poverty reduction in LAC. Section 4 uses a formal model to examine income-support programs for the poor in the context of high informality and draws conclusions for improvements in policy design. Finally, Sect. 5 puts forth the conclusions and implications of the paper.

\section{The evidence}

\subsection{Measuring monetary poverty}

The measurement of poverty first requires establishing a threshold to distinguish the poor from the non-poor. Although it is hard to justify such a discontinuity in the welfare distribution, the practicality and usefulness of poverty lines has been hard to replace.

There are two possible criteria with which to set the poverty line. The first is an absolute poverty threshold. The logic behind an absolute poverty line requires establishing a series of needs to be satisfied by means of a basket of goods and pricing this basket. Caloric intake is a classic element of such baskets. The alternative is a relative poverty line, which can be defined as a fixed rule of the distribution of welfare. For example, a relative poverty line may be defined as $50 \%$ of mean per capita income.

The key difference between these principles is that absolute poverty lines are meant to identify persons with the greatest needs, while relative poverty lines are conceived to adjust to their social context. For example, as incomes grow in a country, the relative poverty line adjusts automatically, reflecting a broadening of the needs that society considers basic. By comparison, absolute poverty will unequivocally fall as incomes grow, provided growth is at least partially shared by the lower tail of the income distribution.

Although most developing countries tend to use absolute poverty lines, there is consistent evidence that these are influenced by relative factors. The first piece of evidence to support this claim is that countries with higher incomes tend to opt for higher poverty lines, even after adjusting for differences in purchasing power, as is shown in Fig. 1. Additionally, after sustained periods of growth, practically the entire population will have overcome a given poverty threshold. When this happens, the poverty rate will remain stagnant at very low levels. Figure 2 illustrates this point for Chile. After a sustained period of poverty reduction, the Ministry of Social Development made a substantial methodological change in how to measure poverty, including an upward adjustment of the poverty line. Although such changes are generally grounded in changes in spending patterns of a reference population, development is an undeniable cause of such changes. Thus, even if not explicitly, poverty lines do adjust to social progress.

As a consequence, differences in national poverty rates reflect not only true differences in poverty between countries, but also the methodological differences in how poverty is measured. Making poverty rates comparable therefore requires the use of a uniform methodology and a line that adjusts for differences in price levels between countries. The World Bank popularized the use of $\$ 1$ per-person-per-day poverty line, which has been 


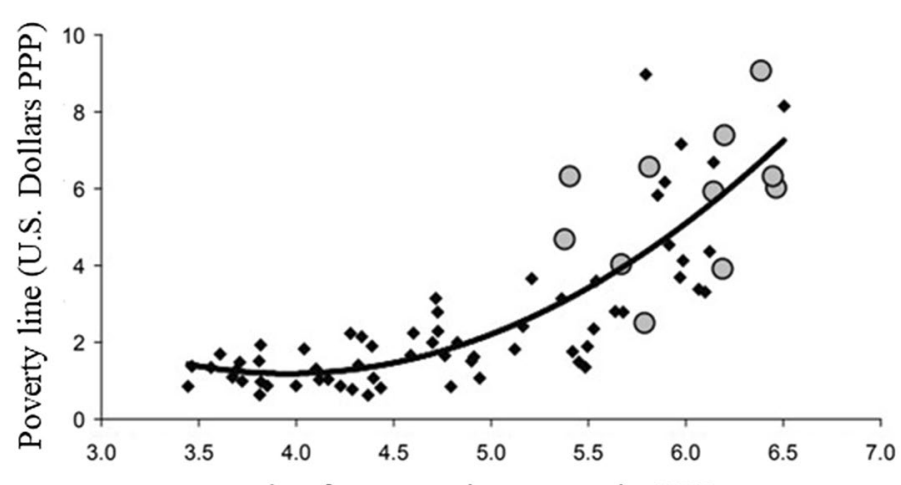

ln of consumption per capita PPP

Fig. 1 Poverty lines and In of consumption per capita [Source: Gasparini et al. (2014) based on Ravallion et al. (2009)]

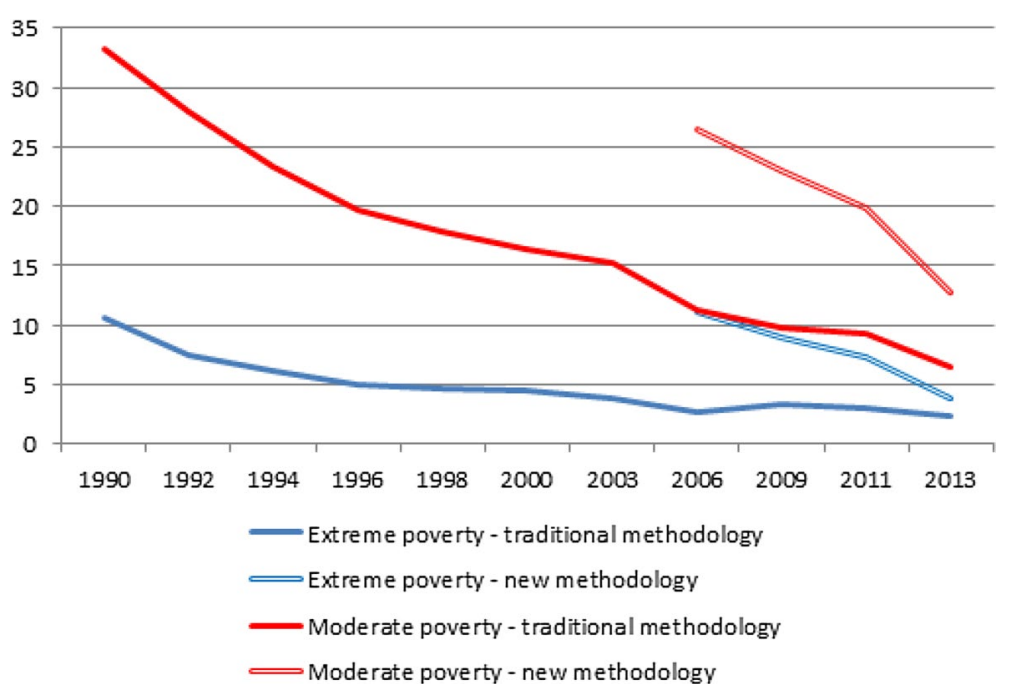

Fig. 2 Poverty rates in Chile (percent) (Source: Prepared by the authors based on information from Chile's Ministry of Social Development)

updated several times to account for inflation in the USA, reaching US\$1.25 in 2005 and US $\$ 1.90$ in 2011 . The poverty line is adjusted by a factor reflecting differences in the purchasing power of the US dollar in each country. Thus, the line is adjusted to each country to reflect the cost of a uniform basket of goods.

Once the poverty line has been set and the poor have been identified, the task that follows is to build a synthetic index from the distribution of income of the poor. Following Sen (1976), a poverty index should comply with two axioms. The first is the monotonicity axiom, which states that a decrease in the income of a person below the poverty line must increase the poverty index. The second is the transfer axiom, which states that any pure transfer from a poor person to someone who is richer must result in an increase in poverty. The headcount ratio does not satisfy either of these axioms, while the poverty gap does not satisfy the transfer axiom.

Foster et al. (FGT) (1984) propose a family of indexes in the following form: 


$$
\operatorname{FGT}(\alpha)=\frac{1}{N} \sum_{i=1}^{N}\left(1-\frac{x_{i}}{z}\right)^{\alpha} 1\left(x_{i}<z\right), \alpha \geq 0
$$

where $x_{i}$ is the income of person or household $i, z$ is the poverty line, $N$ is the total population or number of households, and 1(.) is an indicator function. When $\alpha=0$, this index is the poverty headcount ratio, while $\alpha=1$ delivers the poverty gap. Any $\alpha>1$ will satisfy the transfer and monotonicity axioms. This has popularized the use of FGT(2) as a poverty index, commonly known as poverty gap squared. This paper uses poverty lines adjusted for purchasing power parity and poverty indexes from Foster et al. (1984).

\subsection{Evidence of poverty and inequality}

Table 1 shows several poverty indicators worldwide and for different developing regions since 1981. The period has been one of consistent poverty reduction worldwide. Extreme poverty and moderate poverty have fallen by over 30 and 20 percentage points, respectively. The decline in extreme poverty has reached a point that this benchmark has become of little use, and more moderate poverty lines have become the more relevant benchmark. The fall in poverty is evident in all regions and all indicators, although certain differences prevail. East Asia and the Pacific have been by far the most dynamic in

Table 1 Poverty rates worldwide. Source: Prepared by the authors based on PovcalNet (2017)

\begin{tabular}{|c|c|c|c|c|c|c|c|c|}
\hline & \multicolumn{4}{|c|}{ US\$1.90 PPP } & \multicolumn{4}{|c|}{ US\$3.20 PPP } \\
\hline & 1981 & 1993 & 2002 & 2013 & 1981 & 1993 & 2002 & 2013 \\
\hline \multicolumn{9}{|l|}{ Headcount ratio } \\
\hline East Asia and Pacific & 80.47 & 53.69 & 29.98 & 3.68 & 93.55 & 79.58 & 57.29 & 17.64 \\
\hline Europe and Central Asia & & 5.84 & 6.24 & 2.16 & & 15.72 & 15.12 & 6.81 \\
\hline Latin America and the Caribbean & 16.3 & 14.54 & 13.06 & 4.91 & 31.05 & 28.94 & 26.72 & 11.59 \\
\hline Middle East and North Africa & & 6.67 & 3.23 & 2.31 & & 28.70 & 19.65 & 13.14 \\
\hline South Asia & 54.71 & 44.82 & 38.68 & 14.66 & 85.27 & 80.24 & 75.55 & 51.97 \\
\hline Sub-Saharan Africa & & 59.05 & 56.14 & 40.98 & & 78.06 & 78.02 & 66.48 \\
\hline World total & 42.22 & 33.99 & 25.81 & 10.70 & 57.23 & 54.50 & 47.39 & 28.28 \\
\hline \multicolumn{9}{|l|}{ Poverty gap } \\
\hline East Asia and Pacific & 30.28 & 19.32 & 9.25 & 0.69 & 58.81 & 39.42 & 23.72 & 4.60 \\
\hline Europe and Central Asia & & 1.91 & 1.85 & 0.57 & & 5.44 & 5.38 & 2.15 \\
\hline Latin America and the Caribbean & 6.74 & 6.12 & 5.33 & 2.25 & 13.66 & 12.47 & 11.26 & 4.59 \\
\hline Middle East and North Africa & & 1.26 & 0.60 & 0.47 & & 7.78 & 4.61 & 3.09 \\
\hline South Asia & 17.45 & 11.86 & 9.44 & 2.67 & 40.07 & 33.78 & 30.03 & 15.4 \\
\hline Sub-Saharan Africa & & 27.51 & 25.31 & 15.96 & & 44.72 & 42.96 & 31.86 \\
\hline World total & 17.96 & 11.95 & 8.41 & 3.26 & 31.38 & 25.67 & 20.35 & 9.93 \\
\hline \multicolumn{9}{|l|}{ Poverty gap squared } \\
\hline East Asia and Pacific & 21.69 & 9.14 & 3.92 & 0.23 & 40.42 & 23.2 & 12.50 & 1.72 \\
\hline Europe and Central Asia & & 1.02 & 0.78 & 0.24 & & 2.76 & 2.67 & 0.97 \\
\hline Latin America and the Caribbean & 4.03 & 3.75 & 3.27 & 1.56 & 8.19 & 7.48 & 6.63 & 2.77 \\
\hline Middle East and North Africa & & 0.40 & 0.19 & 0.16 & & 2.97 & 1.63 & 1.12 \\
\hline South Asia & 7.47 & 4.40 & 3.28 & 0.75 & 22.29 & 17.17 & 14.63 & 6.11 \\
\hline Sub-Saharan Africa & & 16.27 & 14.74 & 8.41 & & 30.02 & 28.16 & 19.06 \\
\hline World total & 9.70 & 5.81 & 3.96 & 1.57 & 20.09 & 14.80 & 11.10 & 4.88 \\
\hline
\end{tabular}

PPP purchasing power parity. Unit of measure is the FGT index multiplied by one hundred 
poverty reduction, while progress has been the slowest in relative terms in sub-Saharan Africa. LAC is consistently ranked in the middle compared to the remaining regions: While far from the low poverty levels of Europe and Central Asia, it fares considerably well when compared to regions such as sub-Saharan Africa or South Asia. Poverty levels seem to be historically similar to those of the Middle East and Northern Africa, and also similar to those of East Asia and the Pacific in the most recent measures.

Table 2 shows poverty rates within LAC for the latest years available. As mentioned when discussing Table 1, extreme poverty is very low for most countries in the region: Only one of the 17 countries has a rate that is over $10 \%$, and only five have a rate above $5 \%$. Nevertheless, moderate poverty is still widespread in the region. Moreover, it can be seen that there is substantial variation in the poverty rates.

\subsection{Drivers of poverty reduction}

The evidence reviewed so far shows a consistent decline in the poverty rate, although it does little to explain the drivers behind this trend. Because of the importance of understanding the underlying factors behind the decline in poverty, the remainder of this section is dedicated to its analysis. Schematically, changes in the poverty rate can have three sources, which are explained with the help of Fig. 3. Panel A shows an income distribution and a poverty line (vertical dashed line). Given that the poverty rate is calculated as the percentage of the population below the poverty line, the brown area below income distribution and to the left of the line is a graphical representation of the poverty rate. Panel B shows us that an increase in the value of poverty line, for example because the goods in the basket become more expensive, increases the poverty rate by a

Table 2 Comparison of poverty rates in LAC in 2015. Source: Prepared by the authors based on PovcalNet (2017)

\begin{tabular}{|c|c|c|c|c|c|c|}
\hline \multirow[t]{2}{*}{ Country } & \multicolumn{3}{|c|}{1.90 USD PPP line } & \multicolumn{3}{|c|}{ 3.20 USD PPP line } \\
\hline & Headcount & Poverty gap & Pov. gap sq. & Headcount & Poverty gap & Pov. gap sq. \\
\hline Argentina $^{a}$ & 1.71 & 0.97 & 0.78 & 4.50 & 1.81 & 1.17 \\
\hline Bolivia & 7.11 & 3.44 & 2.30 & 12.86 & 6.07 & 3.95 \\
\hline Brazil & 4.34 & 2.02 & 1.34 & 9.28 & 3.91 & 2.41 \\
\hline Chile & 1.30 & 0.76 & 0.61 & 3.07 & 1.30 & 0.88 \\
\hline Colombia & 5.46 & 2.24 & 1.41 & 13.08 & 5.04 & 2.87 \\
\hline Costa Rica & 1.62 & 0.64 & 0.41 & 4.15 & 1.50 & 0.84 \\
\hline Dominican Republic & 1.94 & 0.48 & 0.20 & 6.87 & 1.99 & 0.86 \\
\hline Ecuador & 4.81 & 2.18 & 1.49 & 11.78 & 4.54 & 2.70 \\
\hline El Salvador & 1.92 & 0.41 & 0.14 & 9.81 & 2.44 & 0.92 \\
\hline Guatemala ${ }^{a}$ & 9.48 & 2.76 & 1.27 & 25.34 & 8.72 & 4.22 \\
\hline Honduras & 17.75 & 6.42 & 3.36 & 34.83 & 14.49 & 8.15 \\
\hline Mexico $^{a}$ & 5.65 & 2.1 & 1.24 & 15.75 & 5.41 & 2.86 \\
\hline Nicaragua a & 3.62 & 0.92 & 0.39 & 13.82 & 3.86 & 1.67 \\
\hline Panama & 2.21 & 0.59 & 0.29 & 7.03 & 2.21 & 1.01 \\
\hline Paraguay & 2.52 & 0.71 & 0.34 & 7.39 & 2.38 & 1.12 \\
\hline Peru & 2.99 & 0.77 & 0.31 & 9.31 & 2.95 & 1.31 \\
\hline Uruguay & 0.27 & 0.10 & 0.06 & 1.38 & 0.36 & 0.16 \\
\hline
\end{tabular}

PPP purchasing power parity. Unit of measure is the FGT index multiplied by one hundred

a Data for 2014 


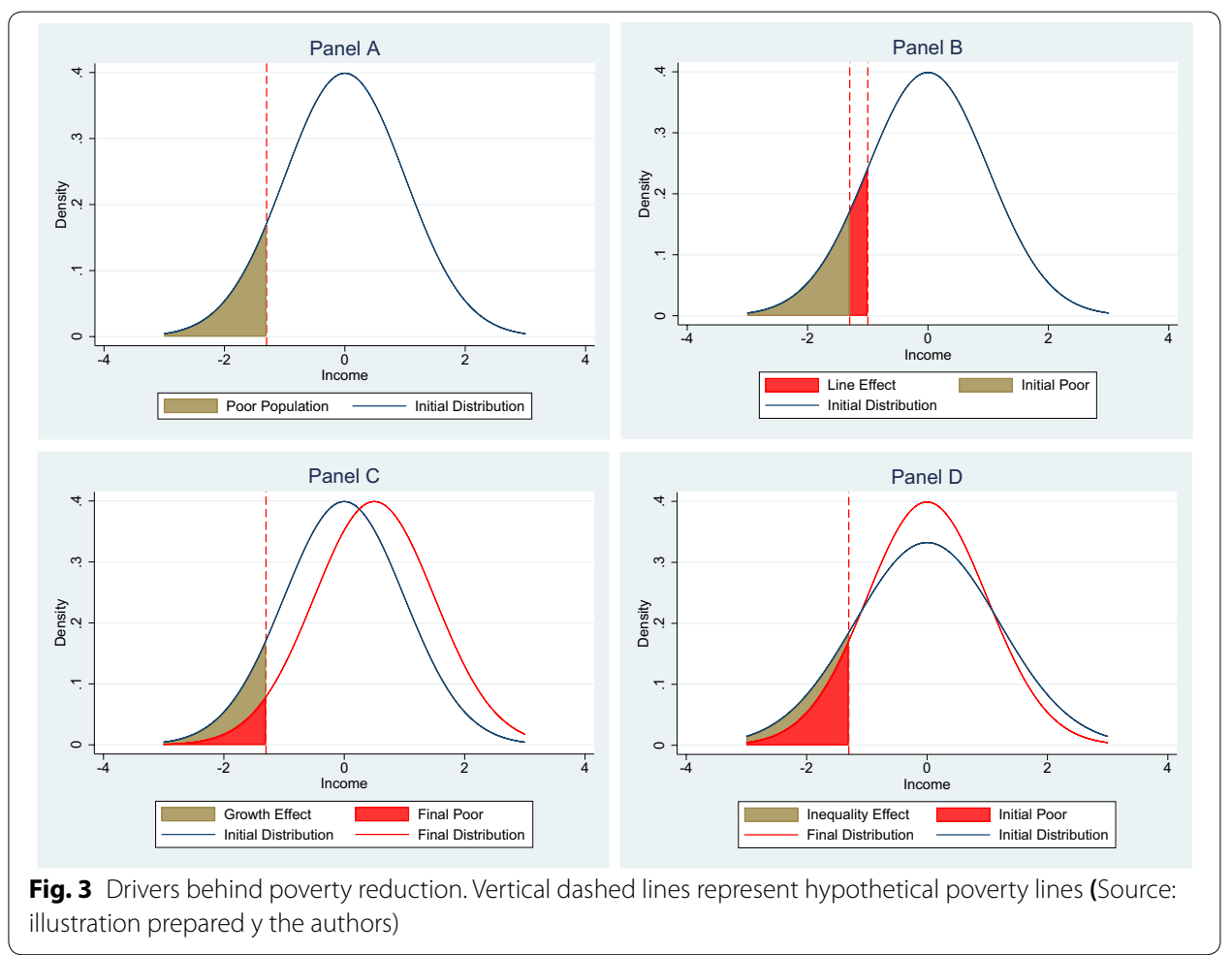

magnitude represented by the red shaded area. This is called the "line effect," and it is a result of changes in the real value of the poverty line. In Panel C, the income distribution is shifted to the right, representing an even increase in incomes. Before the income shift, the poverty rate is represented by the brown and red shaded areas, while only those in the red area remain poor after the income increase. Thus, the brown area represents the fall in poverty resulting from an increase in incomes, called the "growth effect." Last, poverty rates can change because the income distribution becomes more or less egalitarian. These changes are shown in Panel D, where the distribution in red is more even than that in black. If the income distribution were to evolve from the red to the black, poverty would fall by the area shaded brown. This is the "distribution effect."

Simple as it is, this logic provides an outstanding framework to understand the drivers behind the fall in poverty. The following sections are dedicated to studying the growth and the redistribution components of changes in poverty. ${ }^{1}$

\subsubsection{Economic growth}

Economic growth is generally believed to be a necessary factor behind poverty reduction strategies, given that there are constraints to income distribution. As incomes grow, a given poverty line should be accessible to more people. Figure 4 shows the growth in

\footnotetext{
${ }^{1}$ Since we use measures of growth that are adjusted for differences in the purchasing power of the dollar, the line effect is nil by default. The alternative would be to factor out changes in purchasing power from the growth effect based on exchange rate movements and differential inflation, which generate changes in the value of lines expressed in real domestic currency. However, we disregard this calculation as the common practice is to express welfare in a purchasingpower-parity-adjusted measure.
} 


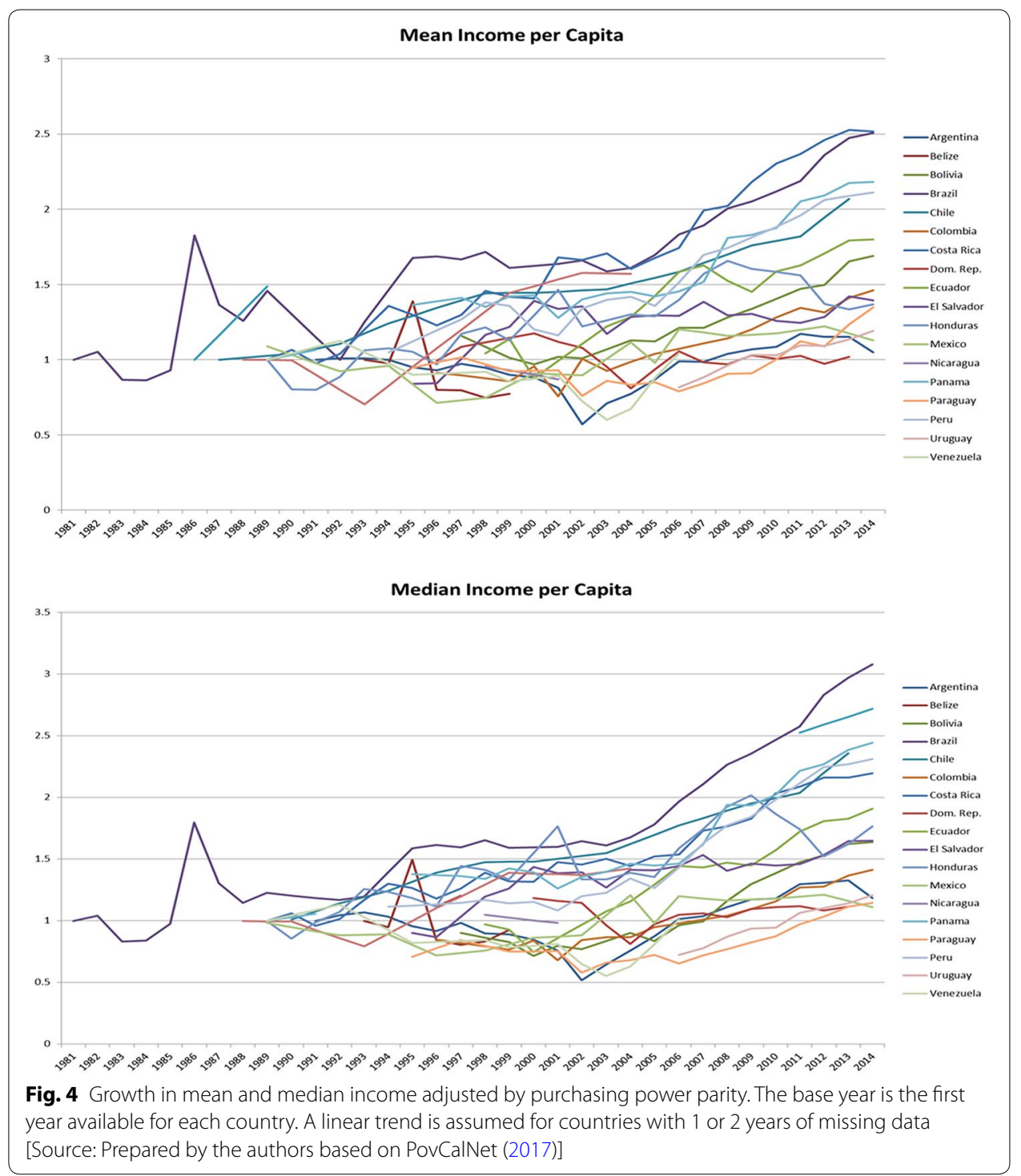

mean and median incomes adjusted for purchasing power parity (PPP) in the region. The figure shows that all countries experienced at least some growth over the 1981-2014 period. On average, mean incomes grew by $69 \%$ from their base year, while median incomes grew by $82 \%$. Additionally, the figure shows the volatile history for which LAC is well known. The decade starting in 1990 had mixed results, as individual country mean growth rates ranged from $-2 \%$ per annum (Venezuela) to over 3\% per annum (Chile, Honduras, Panama). In terms of median income, the growth rates ranged from $-2.8 \%$ per annum (Venezuela and Paraguay) to $4.5 \%$ per annum (Honduras). In the 2000s, there was strong growth in most countries, more than offsetting previous declines in incomes. Growth rates at the beginning of the millennia were quite sensitive to the timing of the crises and in many cases were inflated as a result of the subsequent recovery, but mean 
incomes still grew by between 3 and 4\% per annum in most countries after 2005. Median incomes grew faster, in the range of 4 to even 6\% per annum after 2005.

In all, despite several macroeconomic crises, countries in the region have generally gone through a period of sustained income growth. This growth is expected to have contributed to the fall in poverty discussed previously.

\subsubsection{Inequality}

Latin America has long been recognized as a region with comparatively high levels of inequality. For example, Londoño and Székely (2000) characterized the region as having "excess inequality" given that countries in the region have greater inequality than would be expected for their income levels. Figure 5 illustrates the concept. The figure shows that inequality in Latin America is higher than in any other region in the world. Moreover, even the least unequal countries in the region have inequality levels that would be among the highest in any other region. This shows that inequality is not only high on average, but also a phenomenon that extends throughout the entire region.

The evolution of inequality is a history of ebb and flow. Table 3 shows that reforms in the 1990s tended to increase inequality in most countries in LAC. On the other hand, the past decade of commodity booms and strong economic growth has been accompanied by a generalized fall in inequality in the region. With the exceptions of Costa Rica and Paraguay, the decline in inequality over the past decade was enough to offset the increases in inequality in the earlier period.

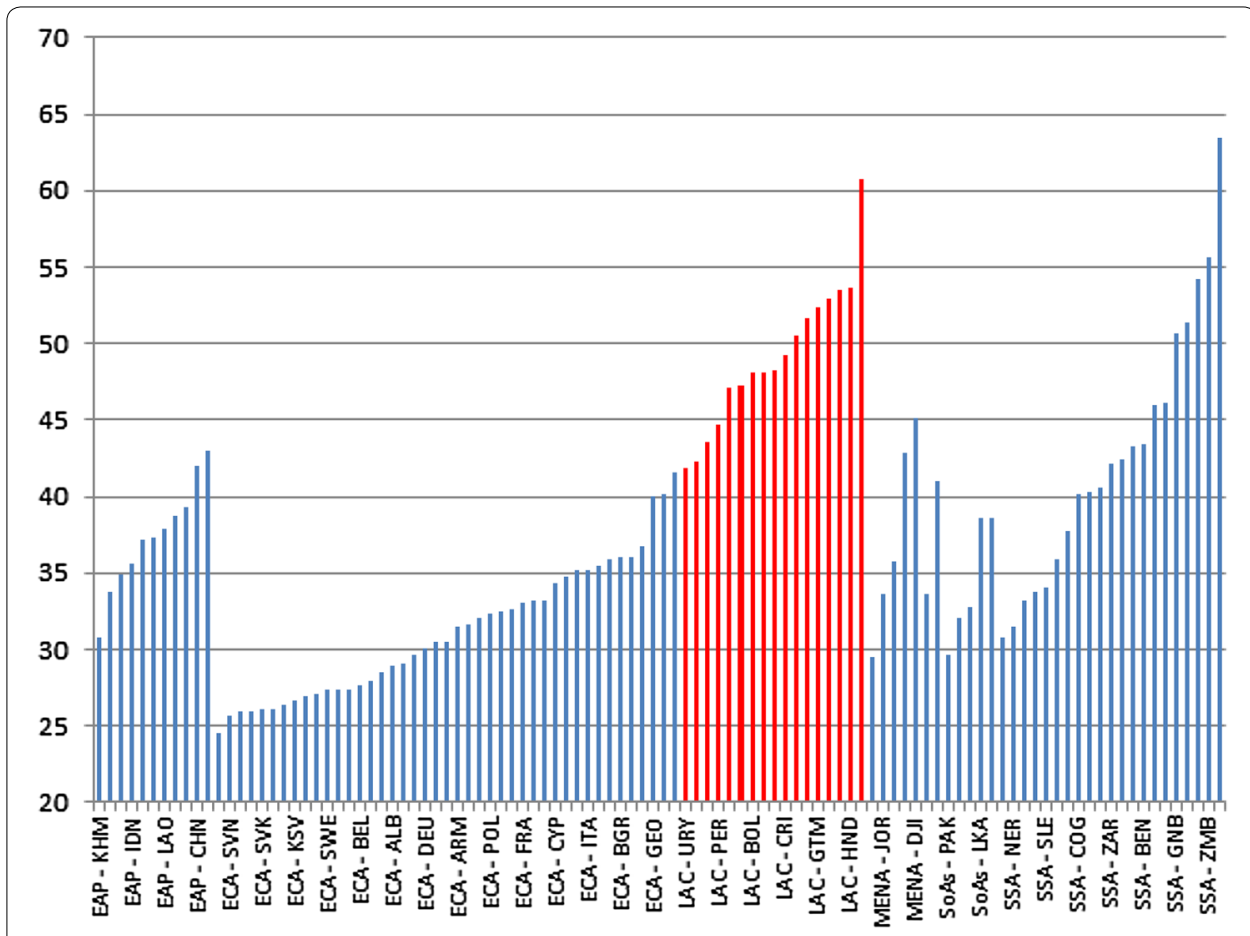

Fig. 5 Gini index worldwide (Source: Prepared by the authors based on the World Bank's World Development Indicators 
Table 3 Gini index in Latin America and the Caribbean since the 1990s. Source: Prepared by the authors based on PovCalNet (2017)

\begin{tabular}{lllllll}
\hline & $\mathbf{1 9 9 0}$ & $\mathbf{1 9 9 5}$ & $\mathbf{2 0 0 0}$ & $\mathbf{2 0 0 5}$ & $\mathbf{2 0 1 0}$ & $\mathbf{2 0 1 4}$ \\
\hline Argentina & & 48.9 & 51.1 & 49.3 & 44.5 & 42.7 \\
Bolivia & & 63.0 & 58.5 & 48.0 & 48.4 \\
Brazil & 60.5 & 59.6 & 59.2 & 56.6 & 53.5 & 51.5 \\
Chile & 57.3 & 55.7 & 55.6 & 52.7 & 51.4 & 50.5 \\
Colombia & & 56.9 & 58.7 & 55.0 & 55.5 & 53.5 \\
Costa Rica & 45.3 & 45.7 & 47.4 & 47.8 & 48.1 & 48.5 \\
Dom. Rep. & & 47.4 & 52.0 & 50.0 & 47.2 & 47.1 \\
Ecuador & & 53.4 & 56.4 & 54.1 & 49.3 & 45.4 \\
El Salvador & & 49.9 & 51.3 & 47.9 & 44.5 & 41.8 \\
Guatemala & & 54.8 & 54.9 & 52.4 & 48.7 \\
Honduras & & 55.5 & 54.7 & 59.5 & 53.4 & 50.6 \\
Mexico & 54.1 & 54.6 & 53.9 & 51.1 & 47.6 & 49.1 \\
Nicaragua & & 56.2 & 56.8 & 51.2 & 45.7 & 47.1 \\
Panama & 58.6 & 57.8 & 57.7 & 54.0 & 51.9 & 50.7 \\
Paraguay & 40.8 & 58.2 & 54.7 & 51.4 & 51.8 & 51.7 \\
Peru & & & 50.8 & 51.8 & 46.2 & 44.1 \\
Uruguay & 42.4 & & & & 45.3 & 41.6 \\
Venezuela & 44.4 & 47.8 & 48.3 & 52.4 & & \\
\hline
\end{tabular}

When the Gini index of a country in a given year was not available, either a linear trend was assumed or that of the closest year was used in its place

One would intuitively believe that the decline in inequality must have contributed to the decline in poverty. However, the claim that both growth and falling inequality played a role in poverty reduction is qualitative. A quantitative decomposition of the decline in poverty into growth and inequality factors would contribute to a more comprehensive understanding of the process behind poverty reduction. The next section takes on that task.

\section{Decompositions of changes in poverty}

There is an extensive series of methods by which changes in poverty can be decomposed into several possible explanatory factors. One of the simplest methodologies, which will be employed here, is a regression-based decomposition. The method consists on estimating a variant of the following equation:

$$
\ln \left(P_{i t}\right)=\alpha+\beta \ln \left(M_{i t}\right)+\gamma \ln \left(I_{i t}\right)+\delta_{t}+\eta_{i}+\varepsilon_{i t},
$$

where $P_{i t}$ is a poverty index, $M_{i t}$ is an income index, $I_{i t}$ is an inequality index, $\alpha$ is a constant, $\delta_{t}$ and $\eta_{i}$ are time and country fixed effects, and $\varepsilon_{i t}$ is an error term. As the previous expression is written in logarithmic form, the parameters $\beta$ and $\gamma$ constitute the elasticities of the poverty rate with respect to income and inequality, respectively. The coefficient $\beta$ is expected to be negative, while $\gamma$ is expected to be positive.

Variants of Eq. (1) are estimated based on data extracted from PovCalNet (2017). This source provides internationally comparable poverty and inequality indexes and data regarding consumption and income adjusted for purchasing power parity. 
Adjustments were made to the data given that the indexes reported are based on the distribution of income for some countries, on consumption for others, and on both for others. We used the countries for which both income and consumption indexes were available to calculate the average ratio between the two and then use this correcting coefficient to countries for which only income-based indexes were provided. All countries for which at least two observations were available were kept in the final sample. The final dataset obtained consists of an unbalanced panel of 135 countries with data from 1984 to 2014, and the results of estimating Eq. (1) are shown in Table 4. Columns (1), (4), and (7) show the results for the full sample of 135 countries; columns (2), (5), and (8) exclude 19 high-income countries from the sample; and columns (3), (6), and (9) limit the sample to countries in LAC. The upper panel shows the results for the US\$1.9 PPP poverty line, while the lower panel uses the US\$3.2 PPP line. Poverty indexes used are the headcount ratio (columns 1-3), the poverty gap (columns 4-6), and the poverty gap squared (columns 7-9).

The elasticities of both growth and inequality have the expected sign throughout the different estimations. At around - 2, the growth elasticity of poverty is similar to that of previous studies (Ravallion and Chen 1997; Ravallion 1997; Kraay 2006). Exclusion of high-income countries has a minimal effect on the parameters estimated when compared to the full sample. However, restricting the estimation to LAC countries has a notable effect on the coefficients. The table shows that the effectiveness of growth for poverty reduction becomes much smaller for all poverty indexes except for the poverty gap squared with the US\$1.9 line. Additionally, inequality reduction is more effective in reducing poverty in LAC than in the other countries. Table 9 in Appendix shows the same results using median consumption instead of the mean. The results remain largely similar in spite of this change.

Higher-than-average inequality is a key factor that explains the difference in coefficients between LAC countries and the full sample. For example, the effect of a small change in income on the poverty rate is the density of the income distribution around the poverty rate. Under certain simplifying assumptions on the distribution of income, high inequality generates a low density around the poverty line, and therefore a low income elasticity of poverty (Bourguignon 2003). Empirical evidence is consistent with this explanation (Ravallion 1997). Additionally, falling inequality generates a proportionally greater reduction in poverty in a place where inequality is high, because this implies larger transfers from rich to poor.

We now assess the quantitative impact of growth and inequality for each country. Table 5 shows the LAC countries in the sample and the change in the poverty rate, income, and inequality expressed in log points. The growth (inequality) effect is calculated as the product of the change in log points in income (inequality) and the elasticity featured in Table 4 . The mean change in the poverty rate is -1.11 log points, while the growth and inequality effects average -0.97 and $-0.12 \mathrm{log}$ points, respectively. These magnitudes indicate that growth has been responsible for the bulk of poverty reduction, although inequality has also played a role. The decomposition of the remaining poverty indexes is featured in Tables 10,11,12, 13, and 14 in Appendix. These show that the growth effect accounts for between 70 and $90 \%$ of the change in the poverty rate, while inequality explains around $12 \%$. 


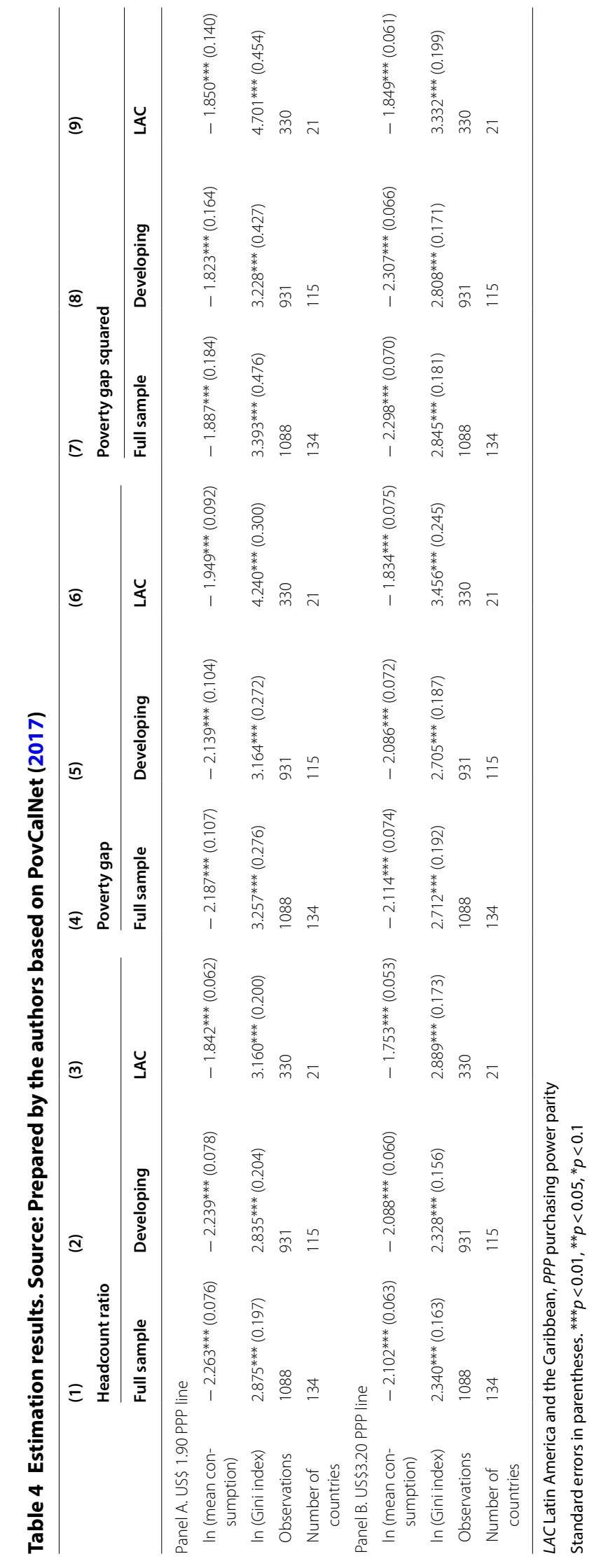


Table 5 Decomposition of changes in headcount ratio (US\$3.20 line). Source: Prepared by the authors based on PovcalNet (2017) and Table 4

\begin{tabular}{|c|c|c|c|c|c|c|c|}
\hline Country & Years in sample & $\log \left(P_{i f} / P_{i 0}\right)$ & $\log \left(M_{i f} / M_{i 0}\right)$ & $\log \left(l_{i f} / l_{i 0}\right)$ & Growth effect & $\begin{array}{l}\text { Inequality } \\
\text { effect }\end{array}$ & Sum \\
\hline Argentina & $1991-2014$ & 0.32 & 0.05 & -0.09 & -0.10 & -0.21 & -0.31 \\
\hline Belize & 1993-1999 & 0.19 & -0.26 & -0.12 & 0.54 & -0.29 & 0.25 \\
\hline Bolivia & 1990-2014 & -0.48 & 0.53 & 0.08 & -1.10 & 0.18 & -0.93 \\
\hline Brazil & $1981-2014$ & -1.79 & 0.92 & -0.12 & -1.93 & -0.28 & -2.21 \\
\hline Chile & 1987-2013 & -2.16 & 0.73 & -0.11 & -1.53 & -0.25 & -1.78 \\
\hline Colombia & $1992-2014$ & -0.46 & 0.38 & 0.04 & -0.80 & 0.09 & -0.71 \\
\hline Costa Rica & 1986-2014 & -2.19 & 1.21 & 0.28 & -2.55 & 0.65 & -1.90 \\
\hline Dom. Rep. & 1986-2013 & -2.68 & 1.13 & -0.08 & -2.37 & -0.19 & -2.55 \\
\hline Ecuador & 1987-2014 & -1.86 & 0.59 & -0.17 & -1.23 & -0.40 & -1.63 \\
\hline El Salvador & 1991-2014 & -1.70 & 0.33 & -0.25 & -0.70 & -0.59 & -1.29 \\
\hline Guatemala & 1986-2014 & -1.75 & 0.78 & -0.24 & -1.63 & -0.57 & -2.20 \\
\hline Haiti & $2001-2012$ & -0.75 & 0.05 & 0.02 & -0.11 & 0.05 & -0.06 \\
\hline Honduras & 1989-2014 & -0.95 & 0.31 & -0.23 & -0.66 & -0.53 & -1.19 \\
\hline Jamaica & 1988-2004 & -1.18 & 0.45 & 0.05 & -0.95 & 0.12 & -0.83 \\
\hline Mexico & 1984-2014 & -0.79 & 0.12 & -0.02 & -0.25 & -0.04 & -0.29 \\
\hline Nicaragua & 1993-2014 & -1.74 & 0.36 & -0.13 & -0.77 & -0.31 & -1.08 \\
\hline Panama & 1989-2014 & -1.88 & 0.78 & -0.15 & -1.64 & -0.35 & -1.99 \\
\hline Paraguay & 1990-2014 & 0.65 & 0.30 & 0.24 & -0.63 & 0.55 & -0.08 \\
\hline Peru & 1985-2014 & -1.77 & 0.75 & -0.10 & -1.57 & -0.23 & -1.80 \\
\hline Uruguay & 1989-2014 & -0.51 & 0.18 & -0.02 & -0.37 & -0.04 & -0.41 \\
\hline Venezuela & 1989-2006 & 0.15 & 0.04 & 0.04 & -0.09 & 0.08 & 0.00 \\
\hline
\end{tabular}

Subindexes 0 and $f$ denote the first and last value available. The variables $P, M$, and $/$ are the poverty rate, mean consumption per capita, and Gini index, respectively

These estimates lead to the conclusion that growth has been the central element behind poverty reduction in LAC. This is not because declines in inequality are ineffective in reducing poverty. Quite the contrary, Table 4 suggests that the elasticity of poverty with respect to inequality is rather large. The reason seems to be that countries in the region have failed to reduce inequality substantially over long periods of time.

Despite the fact that both factors facilitate overcoming the poverty threshold, there is still a nucleus of poor people for whom that progress is elusive. This is because they may be incapable of building the assets (tangible or otherwise) to benefit from these trends. What is more, persistent poverty interferes with the proper upbringing of children, generating an intergenerational transmission. Long-term strategies for poverty reduction therefore require complementing growth and fostering equality, without affecting grow much, with poverty alleviation for the core of the poor population. Unfortunately, adequate identification of this population is quite a challenge, so the following section is dedicated to this issue.

\section{Poverty alleviation programs and targeting}

Sustained economic growth does not automatically spill over to the entire population. Capitalizing on growth often requires the correct set of skills and opportunities, which many may lack. Those incapable of capitalizing on growth may even be done a disservice by it, as growth puts pressure on the prices of vital goods, such as food and land in locations with better access to these opportunities. 
The persistence of these inequalities has long been a rationale for poverty alleviation programs based on ethical grounds. Given that structural factors impede a permanent improvement in the standard of living, programs such as food stamps, subsidized housing, and income support have typically been implemented to mitigate the effect of poverty. Moreover, poverty status may also inhibit proper investments in health and schooling of children-investments that are socially desirable in the long run. This argument adds an efficiency basis for poverty alleviation, and these concerns have explicitly been taken into account in the design of income-support programs such as conditional cash transfer (CCT) programs, which are popular in LAC and require compliance with specified schooling and health criteria for children.

Successful targeting in any poverty alleviation program depends on the possibility of correctly identifying of who is poor and who is not. High-income countries generally rely on employment outcomes to determine eligibility for welfare programs. For example, workers who lose their job qualify for unemployment insurance, workers earning less than a given threshold are entitled to tax credits, and so on. Ownership of assets may also be taken into account to determine eligibility, for example, as is the case of Medicaid in the USA.

However, employment-based criteria have traditionally been considered unsuitable for welfare programs in LAC because of the region's large informal sector. Table 6 shows the informal economy in relation to GDP. Roughly one-third of economic activity in LAC is informal. Table 7 shows informality rates in labor markets. With an unweighted average of $49.9 \%$ and a minimum of over $30 \%$, informality is widespread across the region. In this context, programs like unemployment insurance are virtually impossible to monitor given the difficulty of distinguishing the unemployed from informal workers. What is more, although there is a correlation between informality and poverty, and an inverse correlation between informality and income, these relations are not very strong. Informality rates are large even for middle- and highincome families, and income testing alone would generate a large filtration of public resources to the non-poor.

Given that employment outcomes are an unreliable targeting mechanism in LAC, alternate mechanisms have become necessary, as will be discussed in the following section.

Table 6 Informal economy in 2005 (percent of GDP). Source: Schneider et al. (2010)

\begin{tabular}{lcc}
\hline Region & Weighted average & Median \\
\hline East Asia and the Pacific & 17.50 & 12.70 \\
Europe and Central Asia & 36.40 & 32.60 \\
Latin America and the Caribbean & 34.70 & 33.80 \\
Middle East and Northern Africa & 27.30 & 32.50 \\
High-income Organization for Economic Cooperation and Devel- & 13.40 & 11.00 \\
$\quad$ opment countries & & 19.40 \\
Other high-income countries & 20.80 & 22.20 \\
South Asia & 25.10 & 33.20 \\
Sub-Saharan Africa & 37.60 & 13.20 \\
World & 17.10 & \\
\hline
\end{tabular}


Table 7 Informality rates in labor markets. Source: Prepared by the authors based on SEDLAC (2016)

\begin{tabular}{llll}
\hline & Informality rate (\%) & Correlation with income & $\begin{array}{l}\text { Correlation } \\
\text { with poverty }\end{array}$ \\
\hline Argentina & 38.73 & -0.269 & 0.158 \\
Bolivia & 67.47 & -0.271 & 0.319 \\
Brazil & 46.28 & -0.189 & 0.207 \\
Chile & 31.62 & -0.157 & 0.095 \\
Colombia & 59.04 & -0.314 & 0.289 \\
Costa Rica & 37.70 & -0.231 & 0.177 \\
Dominican Rep. & 52.39 & -0.243 & 0.145 \\
Ecuador & 59.40 & -0.227 & 0.222 \\
Honduras & 64.30 & -0.214 & 0.295 \\
Mexico & 45.16 & -0.135 & 0.218 \\
Panama & 41.92 & -0.266 & 0.352 \\
Peru & 62.33 & -0.318 & 0.288 \\
Paraguay & 46.93 & -0.122 & 0.284 \\
El Salvador & 57.22 & -0.138 & 0.236 \\
Uruguay & 34.90 & -0.231 & 0.135 \\
\hline
\end{tabular}

Informality is measured as the percent of workers without access to the social security system. Data are for the latest year available

\subsection{Targeting in highly informal economies}

As discussed earlier, poverty alleviation programs include a broad range of transfers, some in-kind, others in the form of discounts or refunds (i.e., distortion of relative prices), and also some in cash. Additionally, income-support programs have eligibility requirements that aim to reduce filtrations outside the target population. For poverty alleviation programs, the most immediate measure of whether persons should receive benefits is their income or consumption level, which makes means testing a preferred targeting mechanism. However, administrative agencies have limited power to verify the income of potential beneficiaries in largely informal economies, and means testing has been sidelined as a result.

The literature has proposed a number of alternative targeting mechanisms. Conditionality, for example, has made income-support programs more palatable for non-beneficiaries. If people are going to be getting money, the reasoning goes, they might as well be expected to do something in return. Besley and Coate (1992) argue that conditionality works as a targeting mechanism, as those whose time is too valuable to dedicate to compliance will self-exclude themselves from the program. Conditionality is widely used in LAC, but this design feature has probably more to do with encouraging investments in the human capital of children than with screening the poor from the non-poor.

In a paper that compares the targeting efficiency of different program designs, Alatas et al. (2012) empirically assess whether community-based targeting performs better than proxy means testing and a hybrid mechanism in a field experiment. They find that community-based targeting performs worse than proxy means testing overall, although it performs slightly better at identifying the poorest. However, even though proxy means testing performs better, the authors find that communities where the community-based mechanism is used are more satisfied with the outcome. They also find that a reason for 
this is that communities have an objective function that is more comprehensive than simply a household consumption level.

At the extreme on the trade-off between inclusion and exclusion errors are universal basic income programs. Hanna and Olken (2018) discuss this format in detail, finding several shortcomings in this design. Typically, one would expect individuals to have a positive marginal tax rate, even at low levels of income, and even if universal basic income generates a negative average tax rate for them. However, this is difficult to put into practice in countries where a relatively small fraction of the population pays taxes, because the rest are either exempt or informal. Furthermore, they argue that eligibility requirements not only have an effect on the trade-off between inclusion and exclusion errors, but also on the size of transfers families end up receiving. There is a point where more lenient eligibility implies that a given mass of resources has to be distributed among more families, generating decreasing marginal effects on welfare. In LAC, policymakers have relied heavily on proxy means testing as a targeting mechanism, to the point where proxy means testing has become an "industry standard" (De Wachter and Galiani 2006). Following Barr (1998), proxy means testing has a number of advantages compared to means testing: It does not discourage work effort as much, under some circumstances it requires less information, and it provides a stable assessment of a family's quality of life. Moreover, proxy means testing is especially useful in countries with a high degree of informality, where means testing is unreliable.

However, proxy means testing has its detractors. For starters, there is growing concern regarding its actual efficiency. Stampini and Tornarolli (2012) show that the targeting efficiency of CCT programs in LAC has waned as these programs have grown (Table 8). Although targeting errors are inevitable, large errors will negatively affect the programs' poverty reduction effect and may also generate a sense of unfairness, especially if the program relies on a scoring system that is difficult for the average person to understand. Moreover, programs with large errors may be hard to redesign, as leakages to the middle class increase support for the program.

The next section develops a simple model to assess the targeting efficiency of different mechanisms in a context where workers can choose to work in the formal or informal sector. Overall, the conclusions are quite intuitive and illustrative of the agenda going forward for research and policy.

\subsection{A model of targeting efficiency}

This section is dedicated to examining the targeting efficiency of several alternative mechanisms in situations where workers have employment opportunities in the formal as well as the informal sectors. The difference is that income is unverifiable in the latter, and therefore policymakers cannot use it in means testing. It is assumed that there is a mass $R$ of public revenue to be allocated to transfers with the goal of minimizing a poverty index given a poverty line of $\bar{w}$. Alternative programs can be evaluated along several dimensions. The first dimension is targeting efficiency, which looks at whether the program can be designed so as to transfer income to poor workers. The second is the degree to which the program generates economic distortions, measured as the changes in labor decisions induced by the program. As will become 
Table 8 Targeting efficiency of conditional cash transfer programs (percent). Source: Stampini and Tornarolli (2012)

\begin{tabular}{|c|c|c|c|c|c|}
\hline \multirow[t]{2}{*}{ 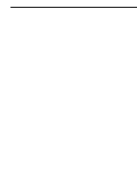 } & \multirow[t]{2}{*}{ Year } & \multicolumn{2}{|l|}{ US\$2.5 PPP line } & \multicolumn{2}{|l|}{ US\$4 PPP line } \\
\hline & & $\begin{array}{l}\text { Percent of poor } \\
\text { covered }\end{array}$ & $\begin{array}{l}\text { Percent of non-poor } \\
\text { beneficiaries }\end{array}$ & $\begin{array}{l}\text { Percent of poor } \\
\text { covered }\end{array}$ & $\begin{array}{l}\text { Percent } \\
\text { of non-poor } \\
\text { beneficiaries }\end{array}$ \\
\hline \multirow[t]{6}{*}{ Argentina } & 2005 & 11.9 & 51.6 & 9.4 & 27.1 \\
\hline & 2006 & 17.8 & 58.0 & 13.9 & 36.7 \\
\hline & 2007 & 22.8 & 61.3 & 17.0 & 38.4 \\
\hline & 2008 & 28.9 & 60.4 & 22.1 & 40.1 \\
\hline & 2009 & 30.2 & 65.1 & 24.1 & 45.9 \\
\hline & 2010 & 47.4 & 75.7 & 42.8 & 54.8 \\
\hline \multirow[t]{5}{*}{ Brazil } & 2003 & 32.8 & 35.3 & 26.5 & 17.8 \\
\hline & 2005 & 38.6 & 39.5 & 31.5 & 19.7 \\
\hline & 2007 & 46.2 & 43.4 & 38.1 & 22.6 \\
\hline & 2008 & 51.0 & 49.2 & 42.2 & 27.4 \\
\hline & 2009 & 55.1 & 50.0 & 46.8 & 28.1 \\
\hline \multirow[t]{3}{*}{ Chile } & 2003 & 41.1 & 68.6 & 30.5 & 41.1 \\
\hline & 2006 & 39.1 & 77.0 & 29.7 & 50.1 \\
\hline & 2009 & 32.7 & 87.1 & 9.1 & 69.6 \\
\hline \multirow[t]{7}{*}{ Ecuador } & 2004 & 49.8 & 46.3 & 44.8 & 22.3 \\
\hline & 2005 & 50.8 & 53.8 & 46.3 & 30.3 \\
\hline & 2006 & 57.7 & 62.4 & 52.8 & 36.5 \\
\hline & 2007 & 59.9 & 59.7 & 55.5 & 34.0 \\
\hline & 2008 & 61.3 & 59.8 & 56.6 & 35.5 \\
\hline & 2009 & 67.3 & 60.2 & 61.1 & 36.9 \\
\hline & 2010 & 64.5 & 65.1 & 58.0 & 40.7 \\
\hline \multirow[t]{5}{*}{ Mexico } & 2002 & 47.5 & 39.9 & 34.3 & 18.0 \\
\hline & 2004 & 48.2 & 53.2 & 36.7 & 27.3 \\
\hline & 2006 & 54.7 & 59.1 & 42.1 & 34.6 \\
\hline & 2008 & 52.9 & 58.6 & 42.9 & 34.4 \\
\hline & 2010 & 53.4 & 61.4 & 42.5 & 35.8 \\
\hline \multirow[t]{5}{*}{ Peru } & 2006 & 5.4 & 14.4 & 3.5 & 5.2 \\
\hline & 2007 & 16.7 & 18.1 & 11.5 & 7.5 \\
\hline & 2008 & 29.7 & 28.7 & 21.2 & 10.4 \\
\hline & 2009 & 32.1 & 32.4 & 23.9 & 12.7 \\
\hline & 2010 & 37.4 & 33.1 & 28.5 & 11.3 \\
\hline \multirow[t]{5}{*}{ Uruguay } & 2006 & 51.2 & 46.8 & 34.4 & 15.5 \\
\hline & 2007 & 64.6 & 44.7 & 42.5 & 13.9 \\
\hline & 2008 & 71.5 & 74.6 & 58.9 & 45.1 \\
\hline & 2009 & 84.2 & 79.8 & 74.6 & 51.8 \\
\hline & 2010 & 84.3 & 84.4 & 77.6 & 57.0 \\
\hline
\end{tabular}

PPP purchasing power parity

clear, distortions in labor decisions reduce the overall effectiveness of a program, even if all beneficiaries are poor.

Both the poverty gap and the poverty gap squared are considered as the relevant indexes. The poverty gap is a very intuitive index, where targeting efficiency of a program simply comes down to how much it can increase the average income of poor families. However, when studying optimal policies, the poverty gap leads to infinite 
solutions, making comparisons difficult. For this reason, the analysis will be complemented with the poverty gap squared, which assigns a greater weight to targeting the poorest of all. This is a valid concern for policy design and a realistic feature of social preferences.

It is assumed that there is a unitary mass of workers who are characterized by two random variables: a wage in the formal sector $w_{f}$ and a wage in the informal sector $w_{i}$. When discussing proxy means testing, an additional feature will be added to workers, but this is not necessary for now. Workers will choose the sector that grants them the greatest income after transfers, which vary depending on the setup of each transfer program. For analytical convenience, it is assumed that the distributions of wages are uniform and independent:

$$
\begin{aligned}
& w_{f} \sim U\left[0, \bar{w}_{f}\right] \\
& w_{i} \sim U\left[0, \bar{w}_{i}\right] \\
& w_{f} \mid w_{i} \sim U\left[0, \bar{w}_{f}\right] \\
& w_{i} \mid w_{f} \sim U\left[0, \bar{w}_{i}\right] .
\end{aligned}
$$

Moreover, it is assumed that $\bar{w}_{f}>\bar{w}_{i}$, so incomes in the formal sector dominate those in the informal sector in a first-order stochastic sense. Although this assumption is largely unnecessary for this paper, it is included because it is a realistic feature of labor markets. Note that absent any transfer program, workers will choose whatever sector generates greater income for them. ${ }^{2}$ Hence, the following expression corresponds to the distribution of wages after the choice of sectors:

$$
\begin{aligned}
& F(w)=\operatorname{Pr}\left(w_{f}<w \vee w_{i}<w\right) \\
& F(w)=\operatorname{Pr}\left(w_{f}<w\right) * \operatorname{Pr}\left(w_{i}<w\right) \\
& F(w)=w^{2} /\left(\bar{w}_{f} * \bar{w}_{i}\right) \text { if } w<\overline{w_{f}} \text { and } w<\overline{w_{l}},
\end{aligned}
$$

where the second expression holds because the distributions of wages are independent and the last expression arises after replacing the appropriate cumulative density functions. It is assumed that $\bar{w}<\bar{w}_{f}$ and $\bar{w}<\bar{w}_{i}$, so $F(w)=w^{2} /\left(\bar{w}_{f} * \bar{w}_{i}\right)$ is the functional form of the cumulative density function in the space that is relevant for measuring poverty. The poverty gap and poverty gap squared that would result absent any public program are given by:

$$
\begin{gathered}
\mathrm{PG}=\int_{0}^{\bar{w}}(\bar{w}-w) \mathrm{d} F(w)=\frac{\bar{w}^{3}}{3 \bar{w}_{f} \cdot \bar{w}_{i}} \\
\mathrm{PGS}=\int_{0}^{\bar{w}}(\bar{w}-w)^{2} \mathrm{~d} F(w)=\frac{\bar{w}^{4}}{6 \bar{w}_{f} \cdot \bar{w}_{i}} .
\end{gathered}
$$

\footnotetext{
${ }^{2}$ Clearly, there are other factors that affect workers' utility and, hence, decisions as to whether to work in the formal or informal sector (Galiani and Weinschelbaum 2012). They are not included here just for purposes of simplicity.
} 


\subsubsection{Optimal targeting}

It is assumed that observing wage opportunities in both sectors implies that the transfer can be a function of available jobs in the formal and informal sectors. Let $t^{*}\left(w_{f}, w_{i}\right) \geq 0$ be the functional form of the optimal transfer. Naturally, the structure of the optimal function will depend on the welfare measure used. First, the poverty gap is considered as the objective function and the properties of an optimal transfer function are enunciated in the following proposition. ${ }^{3}$

Proposition 1 A function $t^{*}\left(w_{f}, w_{i}\right)$ minimizes the poverty gap if the following conditions hold:

i.

$$
\text { If } t^{*}\left(w_{f}, w_{i}\right)>0, w=\max \left\{w_{f}, w_{i}\right\}+t^{*}\left(w_{f}, w_{i}\right) \leq \bar{w}
$$

ii.

$$
\int_{0}^{\bar{w}_{i}} \int_{0}^{\bar{w}_{f}} t^{*}\left(w_{f}, w_{i}\right) \mathrm{d} F\left(w_{f}\right) \mathrm{d} F\left(w_{i}\right)=R
$$

Proposition 1 indicates that the transfers can only be positive for poor workers who do not cross the poverty line as a result of the transfer. The second condition simply states that all the money available is spent. As it turns out, there are an infinite number of functions that can meet these criteria. However, when the poverty gap squared is considered as the objective function, $t^{*}($.) has a unique functional form. Again, this result is shown in the form of a proposition.

Proposition 2 The function $t^{*}\left(w_{f}, w_{i}\right)$ that minimizes the poverty gap squared has the following form:

$$
t^{*}\left(w_{f}, w_{i}\right)= \begin{cases}\bar{t}-\max \left\{w_{f}, w_{i}\right\} & \text { if } \bar{t}>\max \left\{w_{f}, w_{i}\right\} \\ 0 & \text { otherwise }\end{cases}
$$

where $\bar{t}=\sqrt[3]{3 R * \bar{w}_{f} * \bar{w}_{i}}$ and $\bar{t}<\bar{w}$.

In this case, the optimal function raises the income of everyone below $\bar{t}$ to this level, and $\bar{t}$ is set to the value at which the budget restriction is exhausted. The reason for this is that the marginal decrease in poverty is greater the lower the income, and therefore it is always optimal to increase transfers to the poorest families. Additionally, note that the function in Proposition 2 satisfies the conditions in Proposition 1, and so this function also minimizes the poverty gap.

For completeness, the expression for the poverty gap (PG) and the poverty gap squared (PGS) is shown below.

$$
\begin{aligned}
\mathrm{PG}^{*} & =\frac{\bar{w}^{3}-\bar{t}^{3}}{3} \\
\mathrm{PGS}^{*} & =\frac{\bar{w}^{4}-\bar{t}^{3}(4 \bar{w}-3 \bar{t})}{6} .
\end{aligned}
$$

${ }^{3}$ Both Propositions 1 and 2 hold when $R$ is small enough that there is still poverty after the transfers. 
Rather than focusing on the expressions of the poverty gap and the poverty gap squared, greater emphasis will be placed on the form of the transfer functions and the effects they generate. It is understood that unless a transfer function can satisfy the conditions expressed in Propositions 1 and 2, the resulting poverty gap and poverty gap squared will be greater than these values. The study of possible transfer programs will begin with a universal program.

\subsubsection{A universal transfer program}

A universal program is perhaps the simplest welfare program that is feasible to apply. The mass of workers was normalized to equal one, and each worker gets a transfer $R$. Thus, the support of the distributions is shifted as follows:

$$
\begin{aligned}
& w_{f}^{U} \sim U\left[R, \bar{w}_{f}+R\right] \\
& w_{i}^{U} \sim U\left[R, \bar{w}_{i}+R\right] .
\end{aligned}
$$

The cumulative density function for wages is now:

$$
F_{U}(w)=(w-R)^{2} /\left(\bar{w}_{f} * \bar{w}_{i}\right) \quad \text { ifw }>R .
$$

Now, the expressions corresponding to the poverty gap and the poverty gap squared are:

$$
\begin{aligned}
\mathrm{PG}_{U} & =\int_{R}^{\bar{w}}(\bar{w}-w) \mathrm{d} F_{U}(w)=\frac{(\bar{w}-R)^{3}}{3 \bar{w}_{f} \cdot \bar{w}_{i}} \\
\mathrm{PGS}_{U} & =\int_{R}^{\bar{w}}(\bar{w}-w)^{2} \mathrm{~d} F_{U}(w)=\frac{(\bar{w}-R)^{4}}{6 \bar{w}_{f} \cdot \bar{w}_{i}} .
\end{aligned}
$$

One can see that the effect of the universal program on both poverty indexes is identical to that of a reduction in the poverty line by a magnitude of $R$. The universal program is very inefficient in terms of targeting, a result that resembles the discussion by Hanna and Olken (2018) on universal basic income with a high minimum taxable income. This is because everyone receives the transfer, regardless of whether they are above or below the poverty line. However, the universal program generates no distortions: All workers choose the same sector that they would have chosen absent the program. Although universal programs perform poorly in terms of poverty reduction, the fact that they do not affect labor choices is a positive feature of these types of programs. Given that the deficiency of the universal program is the large number of filtrations, the next section looks at a means testing scheme, where it can be ensured that all beneficiaries are poor.

\subsubsection{Means testing transfer program}

Means testing programs rely on direct indicators of the standard of living to determine eligibility. In practice, means testing programs may take into account factors such as a person's assets or rental income. For the purpose of simplicity, it is assumed that the means assessment relies exclusively on the income earned in a formal sector job. If 
formal income is below the poverty line, the worker is granted income support. Since wages in the informal sector are unverifiable, only formal workers are eligible for the public transfer.

It is assumed that workers in the formal sector are entitled to a transfer that is a function of their reported wage, $t\left(w_{f}\right)$. For purposes of simplicity, it is assumed that all poor workers get a positive transfer that is proportional to the distance from the poverty line:

$$
t\left(w_{f}\right)=\left(\bar{w}-w_{f}\right) b \text { if } \bar{w}>w_{f},
$$

where $b \in[0,1]$ is a parameter that determines the degree of phasing out of the program. Since only formal workers are eligible for the transfer and workers choose the formal sector if $w_{f}+t\left(w_{f}\right)>w_{i}$, the following expression shows how the cumulative density function changes as a result of the transfer:

$$
\begin{aligned}
& F_{\mathrm{MT}}(w)= \begin{cases}\operatorname{Pr}\left((1-b) w_{f}+b \bar{w}<w \vee w i<w\right) & \text { if } b * \bar{w}<w<\bar{w} \\
\operatorname{Pr}\left(w_{f}<w \vee w_{i}<w\right) & \text { if } w \geq \bar{w}\end{cases} \\
& F_{\mathrm{MT}}(w)= \begin{cases}\left(w^{2}-b \bar{w} w\right) /\left[(1-b) * \bar{w}_{f} * \bar{w}_{i}\right] & \text { if } b * \bar{w}<w<\bar{w} \\
w^{2} /\left(\bar{w}_{f} * \bar{w}_{i}\right) & \text { if } w \geq \bar{w}\end{cases}
\end{aligned}
$$

Additionally, the cost of the program is represented by the following expression, which can be equated to $R$ to find the (maximum) value of $b$ :

$$
\int_{0}^{\bar{w}} \int_{0}^{w_{f}(1-b)+b \bar{w}} \frac{b *\left(\bar{w}-w_{f}\right)}{\bar{w}_{f} * \bar{w}_{i}} \mathrm{~d} w_{i} \mathrm{~d} w_{f}=\frac{\bar{w}^{3} *\left(\frac{b}{6}+\frac{b^{2}}{3}\right)}{\bar{w}_{f} * \bar{w}_{i}} .
$$

The discussion now turns to the intuition behind the welfare effects of this type of policy. By design, only poor workers get the transfers, no worker crosses the poverty line as a result of the transfer, and all money is spent if $b$ is chosen appropriately. One may be tempted to believe that this type of transfer is optimal in the sense described by Proposition 1. Unfortunately, this is not so. The reason is that many workers sacrifice better employment opportunities in the informal sector to become eligible for the transfer. This is a distortion caused by the welfare program. Figure 6 shows that the after-transfer distribution of income

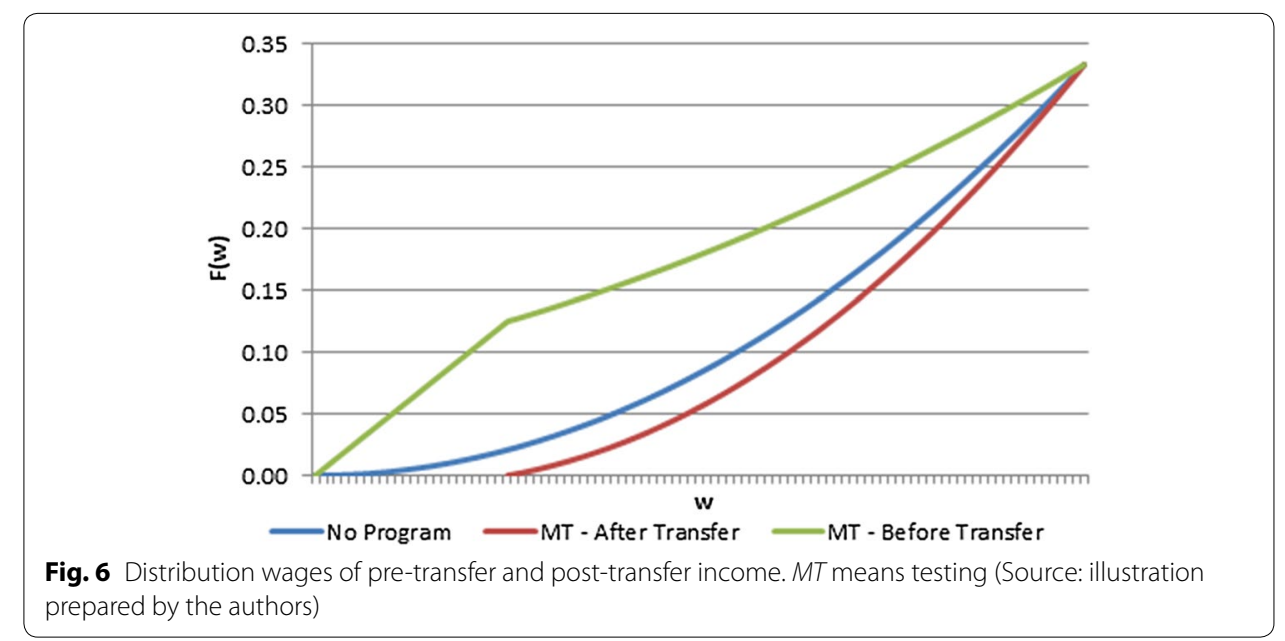


dominates the distribution absent a program in a first-order-stochastic sense, but the pretransfer distribution is dominated by the distribution absent a program. Thus, the effectiveness of the program in terms of reducing the poverty gap is partly offset by the foregoing of productive jobs in the informal sector.

In terms of the poverty gap squared, it is noteworthy that because one can choose $b>0$, this transfer mechanism has a clear pro-poor nature. However, wages are not equalized for the poorest and the overall effect is therefore suboptimal unless the budget is sufficient to lift everybody out of poverty. Moreover, even if one allowed for a more flexible functional form, the poverty gap squared under optimal targeting would still be unattainable. Again, the reason for this is that the transfer program channels workers away from more productive jobs in the informal sector.

In spite of this, it is clear that poverty falls as measured by both indexes. The expression of the poverty gap and the poverty gap squared is

$$
\begin{aligned}
& \mathrm{PG}_{\mathrm{MT}}=\frac{\bar{w}^{3}}{3 * \bar{w}_{f} \cdot \bar{w}_{i}} * \frac{1-\frac{3}{2} * b+\frac{1}{2} * b^{3}}{1-b} \\
& \mathrm{PGS}_{\mathrm{MT}}=\frac{\bar{w}^{4}}{6 \bar{w}_{f} \cdot \bar{w}_{i}} *(b+1)(b-1)^{2} .
\end{aligned}
$$

It is easy to verify that these indexes are smaller than corresponding ones absent means testing, and poverty is reduced as a result of the program. An interesting question is whether universal programs can reduce poverty more than means testing programs. In terms of the poverty gap, it seems logical that means testing is more effective because it generates no filtration to the non-poor. However, it is technically possible that, if filtration is low (e.g., because practically everyone is poor) or if distortions caused by means testing are large, then a universal program may be more effective at reducing the poverty gap than a means testing program. In terms of the poverty gap squared, this is again possible, but more unlikely because the design of the transfer is more pro-poor under means testing.

\subsubsection{A proxy means testing program}

To consider the effect of a proxy means testing program, it is assumed there is a series of subsets $X=\left\{x_{1}, x_{2}, \ldots, x_{N}\right\}$ that constitute a partition of the space of possible wages. The proportion of members in each group is $p_{x_{i}}$, with $\sum_{i} p_{x_{i}}=1$. Figure 7 is a graphical representation of such possible subsets.

Let us assume that the government transfers $t_{x}$ to all members of group $x$ and that the transfer is only conditional on belonging to the group, may differ between groups, and may be equal to zero. The poverty indexes that arise from the transfer are:

$$
\sum_{i=1}^{N} \int_{0}^{\bar{w}} v\left(w+t_{x_{i}}\right) d F\left(w \mid x_{i}\right) p_{x_{i}},
$$

where $v(w)=(\bar{w}-w) 1\{\bar{w}>w\}$ for the poverty gap and $v(w)=(\bar{w}-w)^{2} 1\{\bar{w}>w\}$ for the poverty gap squared. Let $T(X)$ denote a series of transfers for groups $\left\{x_{1}, x_{2}, \ldots, x_{N}\right\}$. 


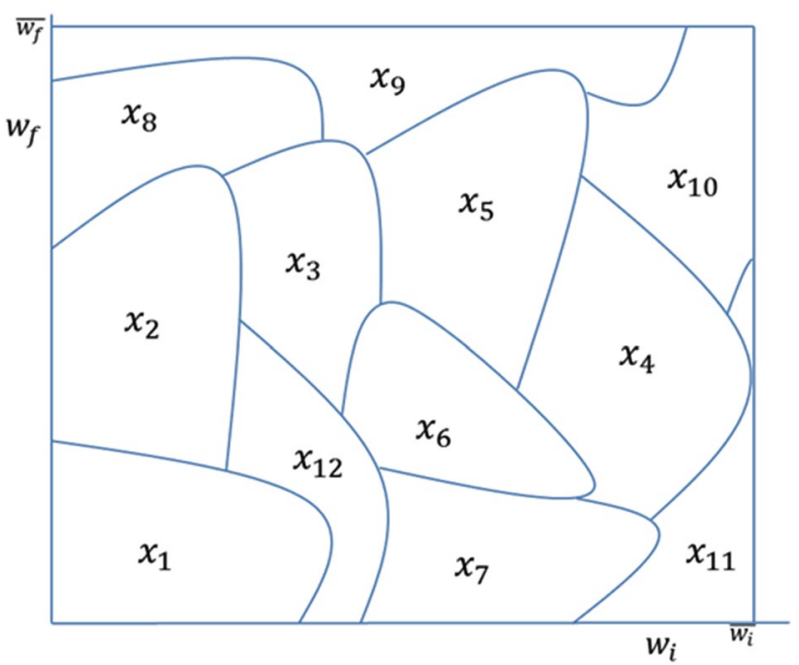

Fig. 7 Graphic representation of the distribution of wages and characteristics

De Wachter and Galiani (2006) show that the optimal targeting rule corresponds to the following expression:

$$
T^{*}(X)=\arg \max _{T(X)} \sum_{x_{i}}\left(\int_{0}^{\bar{w}} v(w)-v\left(w+t_{x_{i}}\right) d F\left(w \mid x_{i}\right)-\lambda t_{x_{i}}\right) p_{x_{i}},
$$

where $\lambda$ is a parameter that can be scaled so that total spending equals available revenue. Intuitively, this rule says that positive transfers must be assigned to groups for which poverty reduction is larger than $\lambda t_{x_{i}}$.

Note that the proxy means testing program generates no distortion in the formality decision, as wages are not taken explicitly into account when determining the transfer. Thus, in terms of targeting efficiency, proxy means testing programs must be at least as good as universal programs, as granting every group the same transfer is feasible within this framework. The reason for this is because it has been assumed that $x$ is strictly exogenous. The implications of potentially endogenous characteristics will be discussed in the following section.

Given a value $\lambda$, the transfer to a group will fall the greater the share of non-poor members if $v($.$) is the poverty gap, or the higher incomes are in a group if v($.$) is the$ poverty gap squared. Figure 8 illustrates a case where members of group $x^{\prime}$ receive larger transfers than those of group $x^{\prime \prime}$ in spite of the fact that many the poorest workers belong to group $x^{\prime \prime}$. This is because the poorest workers are undistinguishable from other non-poor workers, and the high degree of inclusion errors outweighs the benefits of granting the poorest a greater transfer.

Overall, the targeting efficiency of proxy means testing depends on whether the space of characteristics $X$ can separate the poor from the non-poor and identify the poorest, in particular. The following propositions determine conditions under which proxy means testing minimizes the poverty gap and the poverty gap squared: 


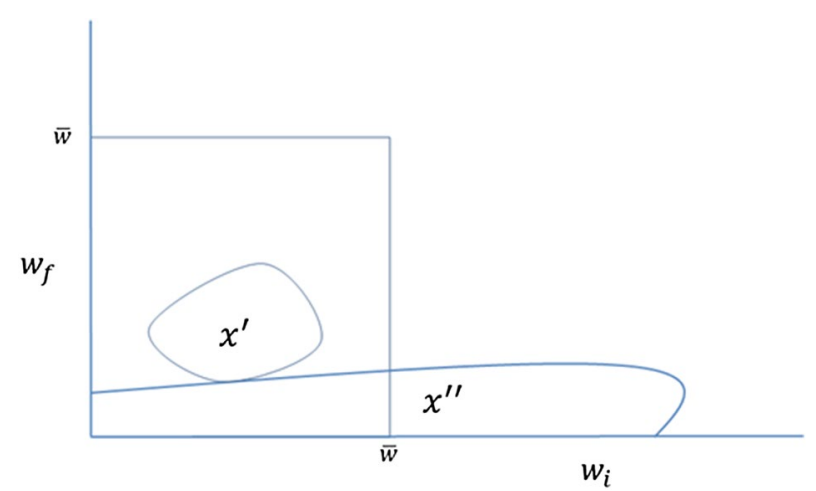

Fig. 8 Characteristics and transfers

Proposition 3 Assume there is a subset $X_{p}=\left\{x_{1}^{p}, x_{2}^{p}, \ldots, x_{m}^{p}\right\} \subset X$ such that all workers in $X_{p}$ are poor. Additionally, assume there exist a series of transfers $T\left(X_{p}\right)$ such that $\max \left\{w_{f}, w_{i}\right\}+t(x)$ for all workers $x \in X_{p}$, and $\sum_{i=1}^{m} t\left(x_{i}^{p}\right) p_{x_{i}^{p}}=R$. Then, $T\left(X_{p}\right)$ minimizes the poverty gap.

Proposition 4 Let $\bar{t}$ be the same value found in Proposition 2. Assume there is a series of subspaces $X_{p}=\left\{x_{1}^{p}, x_{2}^{p}, \ldots, x_{m}^{p}\right\}$ such that

$$
\begin{aligned}
& x_{1}^{p}=\left[0, \frac{\bar{t}}{m}\right] *\left[0, \frac{\bar{t}}{m}\right] \\
& x_{2}^{p}=\left[0,2 \frac{\bar{t}}{m}\right] *\left[0,2 \frac{\bar{t}}{m}\right]-x_{1}^{p} \\
& \ldots \\
& x_{m}^{p}=[0, \bar{t}] *[0, \bar{t}]-x_{1}^{p}-x_{2}^{p}-\ldots-x_{m-1}^{p} .
\end{aligned}
$$

Additionally, assume a transfer function $t(x)=E(w \mid x)$ for all $x \in X_{p}$. If $m$ approaches infinity, then the transfer function is efficient.

Once again, the conditions set by Proposition 3 seem reasonable. In fact, the greatest requirement is that the space of characteristics identifies a subset of the poor population; it requires neither identifying all the poor people nor separating the poor from the nonpoor. However, as argued in Proposition 1, these conditions seem feasible only because the poverty gap is imperfect as a poverty measure. On the other hand, conditions set by Proposition 4 are unrealistic, as these conditions imply being able to infer the wage level of all of the poorest workers.

\subsubsection{The combination of multiple programs}

Both means testing and proxy means testing programs can leave poor families without support. In this context, it is common for policymakers to combine these types of programs to ensure that more poor families receive at least some coverage. This section considers the effect of combining different programs to cover this gap, starting by 


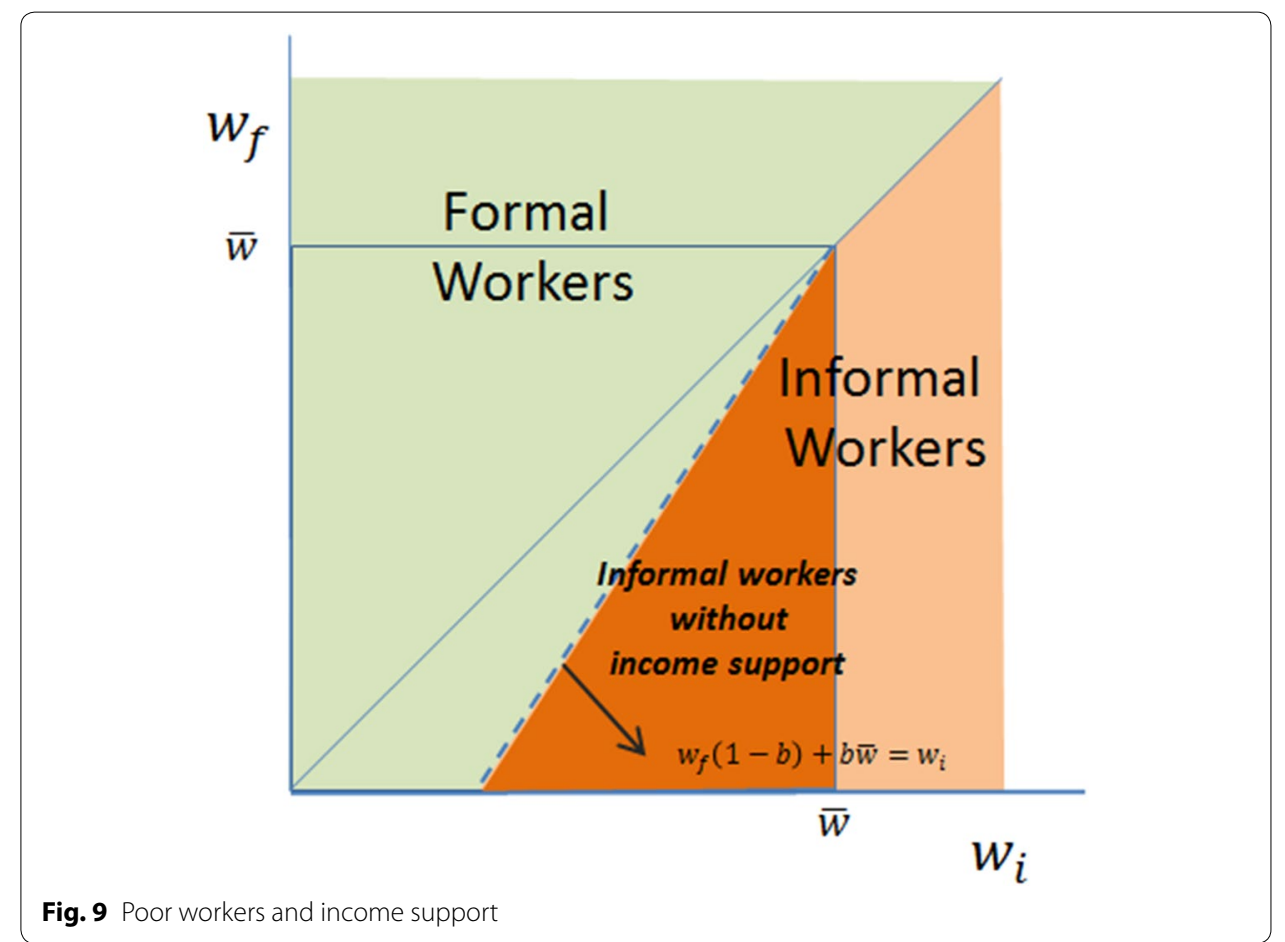

considering the basic structure of the means testing program in Fig. 9. Note that the poor families who do not receive income support belong to the informal sector (shown in dark orange), and the goal is therefore to study transfer programs that are conditional on informality.

As has been argued previously, targeting efficiency is maximized if income support can be made a decreasing function of income. However, because incomes in the informal sector are unobservable, this is not feasible. Instead, one first considers combining the means testing program with a lump-sum transfer for all informal workers. As readers can probably guess, this program is likely to be rather inefficient, especially if there are a large number of informal workers who are non-poor. As a consequence, this section also examines the effects of combining the means testing program with a proxy means testing for informal workers.

Because these programs are more general than means testing, they can trivially do as well as means testing in terms of poverty reduction. However, the model predicts that conditioning income support on informality tends to increase the latter. In the context of the model, this is not particularly disturbing, but in reality, the costs associated with informality are likely to be much larger than those shown here.

\subsubsection{A means testing program with a transfer to informal workers}

The section examines the case of combining a means testing program with lump-sum payments to informal workers. It is again assumed that workers choose a sector and are granted income support equal to $t_{f}\left(w_{f}\right)=b \bar{w}+(1-b) w_{f}$ if $w_{f}<\bar{w}$, or a lump sum of $t_{i}$ if they choose the informal sector. Assuming $t_{i}<b \bar{w}$, Fig. 10 shows how workers allocate 
themselves into the formal and informal sectors. One can see that, compared to the case where there is no transfer to informal workers $\left(t_{i}=0\right)$, the inclusion of the second transfer encourages more workers to choose the informal sector.

The total cost of transfers to formal workers is given by:

$$
C_{f}=\frac{1}{\bar{w}_{i} \cdot \bar{w}_{f}}\left\{\bar{w}^{3}\left[\frac{b-b^{2}}{6}+\frac{b^{2}}{2}\right]-\frac{t_{i} b}{2} \bar{w}^{2}\right\} .
$$

Note that this is a generalization of the cost of the means testing program; a value of $t_{i}=0$ delivers the same expression seen previously. Additionally, the cost of transfers to informal workers is given by:

$$
C_{i}=\frac{1}{\bar{w}_{i} \cdot \bar{w}_{f}}\left\{t_{i} \bar{w}^{2} \frac{(1-b)}{2}+t_{i}^{2} \bar{w}_{i}+\frac{t_{i}^{3}}{2}\right\} .
$$

The appropriate expressions for the poverty gap and the poverty gap squared are given by:

$$
\begin{aligned}
& \mathrm{PG}_{M}=\frac{1}{(1-b) \bar{w}_{i} \cdot \bar{w}_{f}}\left\{\frac{\bar{w}^{3}}{3}\left[1-\frac{3}{2} b-\frac{b^{3}}{2}\right]-\bar{w}^{2} \frac{t_{i}}{2}[1-b(2-b)]\right\} \\
& \mathrm{PGS}_{M}=\frac{1}{\bar{w}_{i} \cdot \bar{w}_{f}}\left[\frac{\bar{w}^{4}}{6}(1+b)(1-b)^{2}+\frac{\bar{w}^{3}}{6} t_{i}(1-b)^{2}\right] .
\end{aligned}
$$

Given that the goal is to minimize the poverty index, one can find an optimal solution by choosing $t_{i}$ and $b$ that minimizes these poverty measures subject to the budget constraint:

$$
\begin{aligned}
& \min _{t_{i}, b} P_{m} \\
& \text { s.t. }: R \geq \frac{1}{\bar{w}_{i} \cdot \bar{w}_{f}}\left\{\bar{w}^{3}\left[\frac{b-b^{2}}{6}+\frac{b^{2}}{2}\right]-\frac{t_{i} b}{2} \bar{w}^{2}+t_{i} \bar{w}^{2} \frac{(1-b)}{2}+t_{i}^{2} \bar{w}_{i}+\frac{t_{i}^{3}}{2}\right\},
\end{aligned}
$$

where $\mathrm{P}_{M}$ is a poverty index, like $\mathrm{PG}_{M}$ or $\mathrm{PGS}_{M}$. The solution to this problem requires equalizing the marginal reduction in poverty per dollar for $b$ and $t_{i}$ :

$$
\frac{\partial P_{m}\left(t_{i}^{*}, b^{*}\right) / \partial t_{i}}{\partial\left(C_{f}\left(t_{i}^{*}, b^{*}\right)+C_{i}\left(t_{i}^{*}, b^{*}\right)\right) / \partial t_{i}}=\frac{\partial P_{m}\left(t_{i}^{*}, b^{*}\right) / \partial b}{\partial\left(C_{f}\left(t_{i}^{*}, b^{*}\right)+C_{i}\left(t_{i}^{*}, b^{*}\right)\right) / \partial b} .
$$

There are at least two problems with combining these policies, which are shown in Fig. 10. The first is the possibility that many informal workers are non-poor, and therefore the program will have a large number of filtrations (i.e., leakages). The second is that the transfer to informal workers increases the incentive to join this sector, both for poor and for non-poor workers. As a consequence, transfers to informal workers are an inefficient mechanism to provide income support to poor and informal workers, and given 


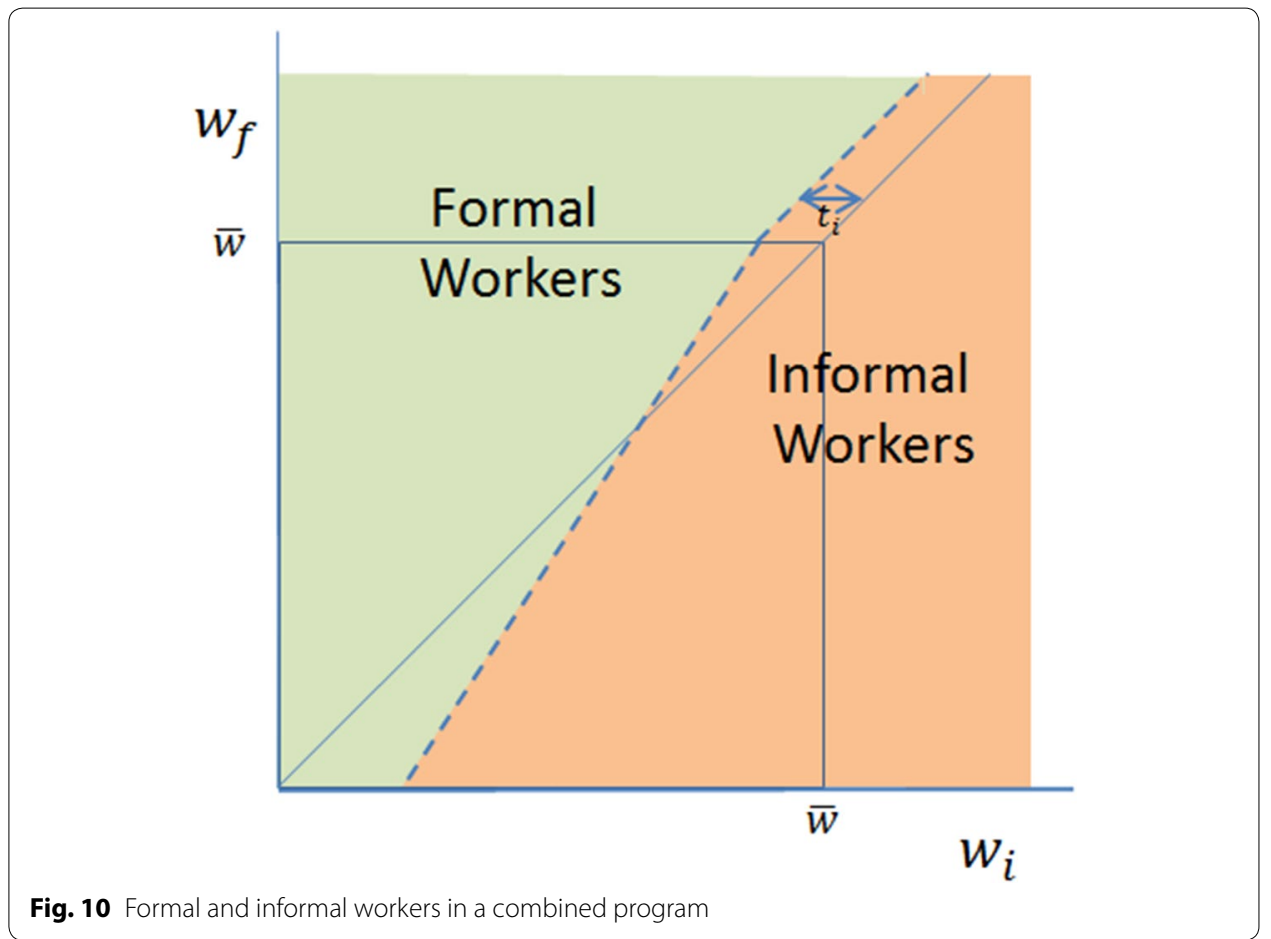

these issues one would expect $t_{i}^{*}$ to be rather small. These undesirable properties can be mitigated by means of a proxy means testing transfer to informal workers, which is discussed in the following section.

\subsubsection{A means testing program with a proxy means transfer to informal workers}

In examining the effect of proxy means testing programs, we argued that their overall effectiveness in terms of poverty reduction depends on the empirical relation between observable characteristics and income. When a set of characteristics are a good predictor of low income, a large transfer can be assigned to this group to reduce poverty. In this case, the total effect of proxy means testing as a complement to means testing is more complex because many workers will be eligible for both subsidies and will only be able to choose one. Moreover, the proxy means testing complement will generally induce workers to choose the informal sector relative to the case where income support is provided by means of a means testing program alone.

Because the effect of the proxy means testing complement depends crucially on the relation between the observable characteristics and income, it is hard to generalize results. Instead, we examine the effect of proxy means testing complements by studying three cases of different possible relations between characteristics, income, and formality status.

\subsubsection{Case 1: Observable characteristics identify poor informal workers}

Figure 11 shows the case where observable characteristics identify workers who under a means testing program alone would be poor and informal. In this case, workers with characteristics $x^{\prime}$ would receive a subsidy that is conditional on being informal and 


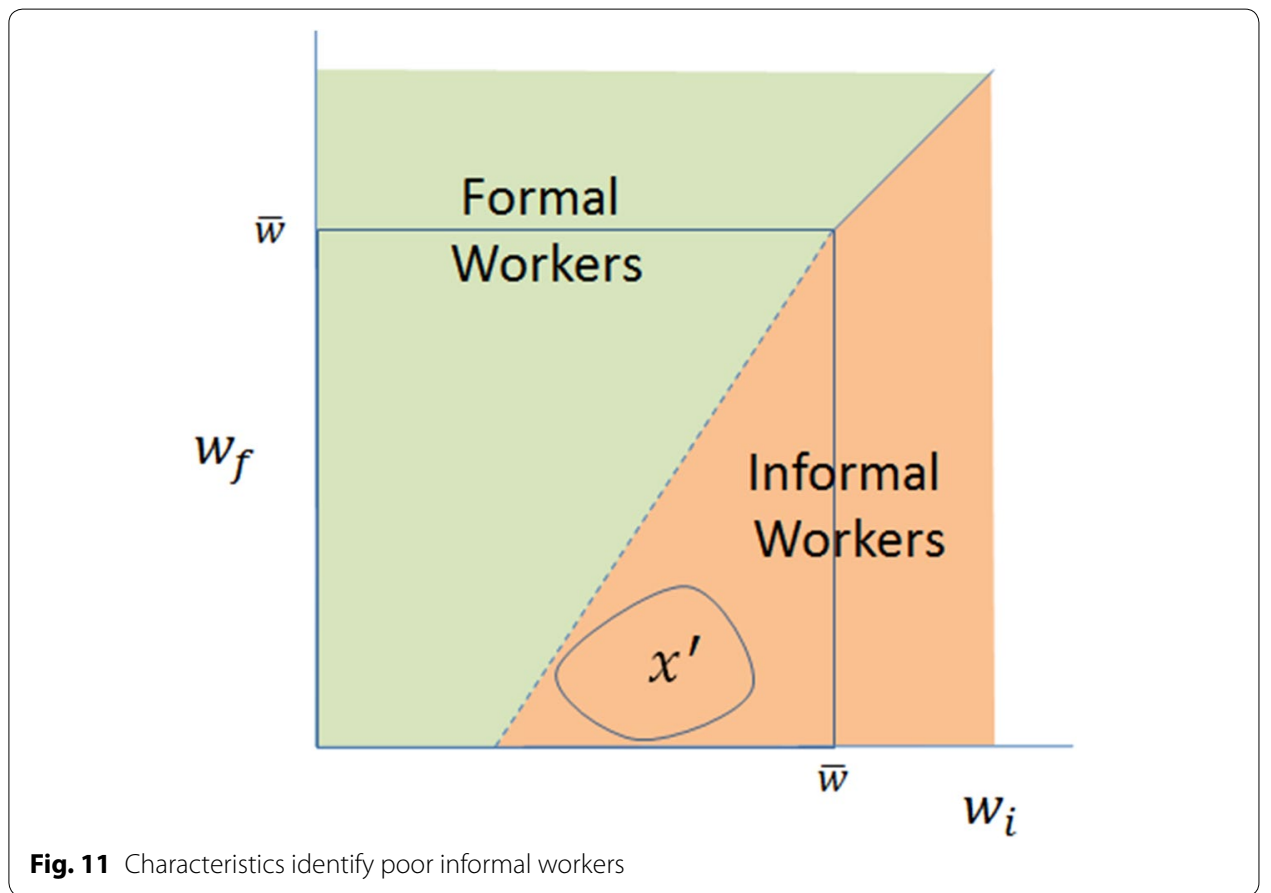

holding these characteristics. The magnitude of the subsidy will depend on the specific welfare measure used and on how poor workers in $x^{\prime}$ are relative to the rest of the poor. Relative to the case of means testing alone, one see that in this case there is no effect on formality.

\subsubsection{Case 2: Observable characteristics identify very poor formal workers}

Figure 12 shows the case in which observable characteristics identify the poorest families. In this case, it is more efficient to give informal workers with characteristics $x^{\prime \prime}$ a large subsidy. This is because these characteristics are strong predictors of poverty, and therefore making transfers to this group is very efficient. Moreover, while the means testing transfer has a limited capacity to transfer income to these people (the maximum transfer is $b \bar{w}$ ), policymakers have much more discretion to make transfers by means of proxy means testing. As a result, the expected transfer for this group would be rather large. However, Fig. 12 also shows the undesirable consequences of giving this group a large subsidy: These workers would mainly choose the informal sector in order to qualify for the lump-sum payment.

\subsubsection{Case 3: Observable characteristics identify nearly non-poor formal workers}

Finally, Fig. 13 shows a situation where the observable characteristics identify workers who are poor but are on the verge of graduating from this status. In this case, it is optimal not to grant workers with characteristics $x^{\prime \prime \prime}$ any additional transfer. Rather, if negative transfers are feasible, it may even be optimal to reduce the transfers to $x^{\prime \prime \prime}$ in order to increase the budget available for the remaining poor. Given that the possibility of using proxy means testing transfers is discarded, there are no additional effects regarding the choice between sectors relative to a stand-alone means testing program. 


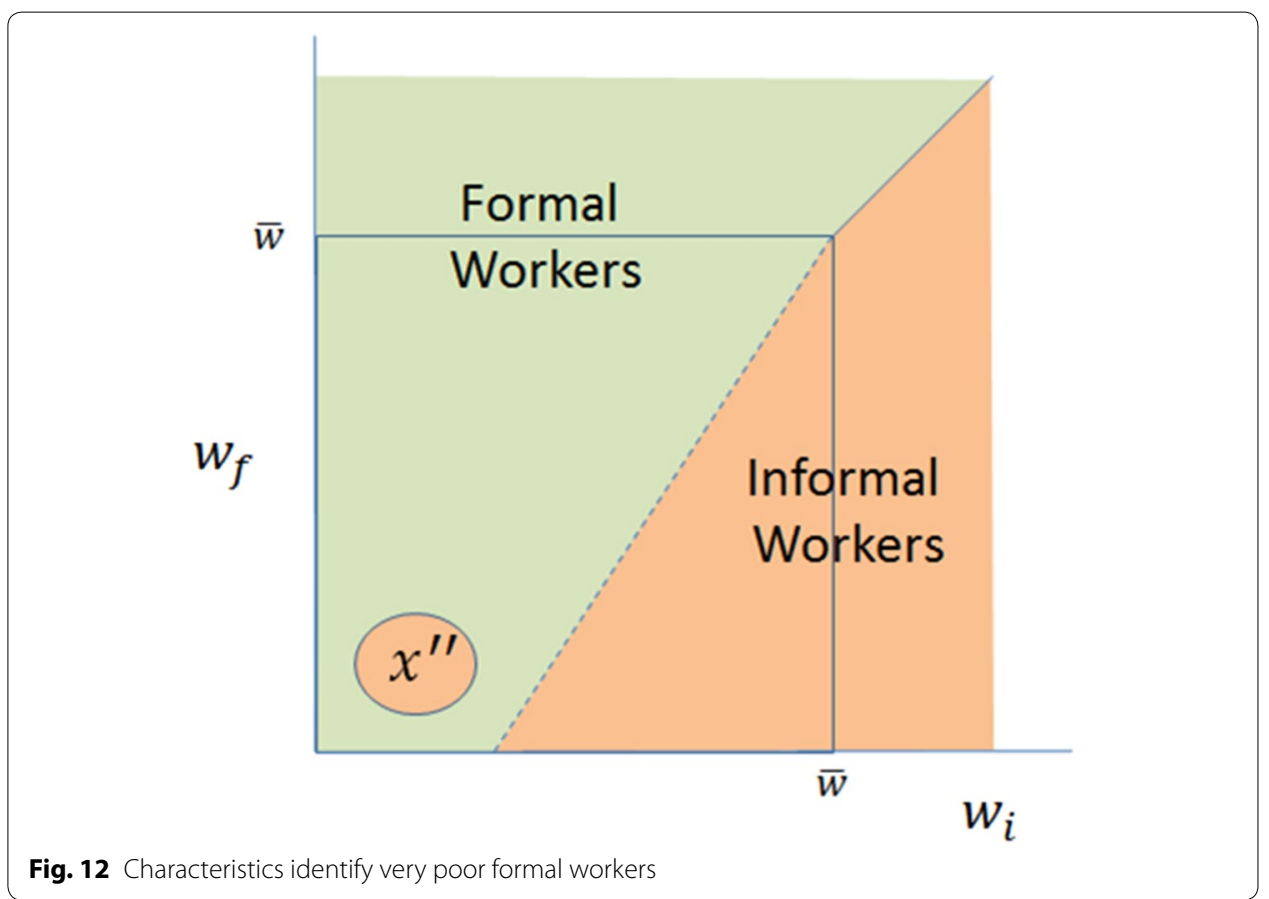

\subsubsection{Welfare programs and the budget restriction of the government}

The analysis so far has assumed that the budget available for redistribution was given. This extension to the model shows that raising revenues has several adverse consequences in the presence of a large informal sector. Since taxes can only be borne by formal workers, these workers will tend to switch toward the informal sector as the

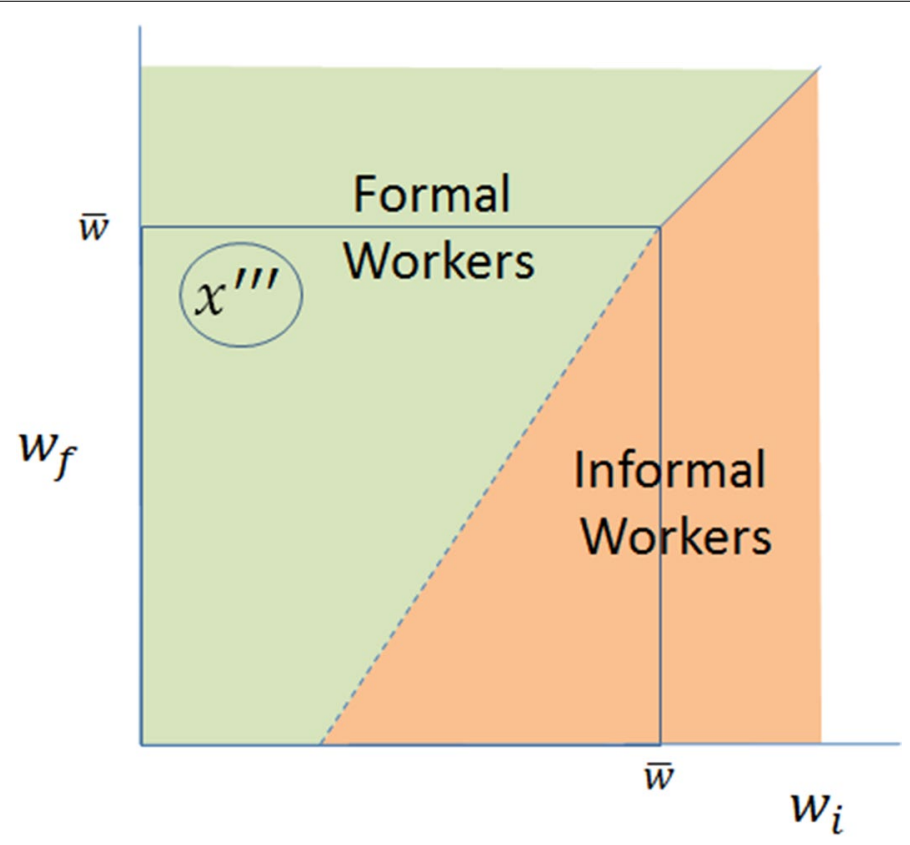

Fig. 13 Characteristics identify nearly non-poor formal workers 
government raises tax rates, dampening revenues. The government will either have to raise taxes further or make do with the diminished revenue. As a result, both the excess in taxation and the slack of revenues will serve as a measure of the costs of informality.

As previously, it is assumed that workers choose the sector that generates the largest disposable income. It is assumed that formal workers pay taxes at a uniform rate $\tau$ and all workers who are poor receive a transfer with the same structure as the former example. Hence, disposable income (utility) for formal workers is:

$$
U_{f}=w_{f}(1-t)+t_{f}\left(w_{f}\right)
$$

where

$$
t_{f}\left(w_{f}\right)=\left\{\begin{array}{ll}
{\left[\bar{w}-(1-\tau) w_{f}\right] b} & \text { if } \bar{w}>(1-t) w_{f} \\
0 & \text { if } \bar{w} \leq(1-t) w_{f}
\end{array} .\right.
$$

For informal workers, utility is given by their wage and a transfer for all non-registered workers. Hence, disposable income for informal workers is:

$$
U_{i}=w_{i}+t_{i}
$$

Workers choose the formal sector whenever $U_{f}>U_{i}$ and choose the informal sector otherwise. Hence, the ratios of informal and formal workers are given by:

$$
\begin{aligned}
& S_{i}=\frac{1}{2} \frac{1}{\bar{w}_{i} \cdot \bar{w}_{f}}\left\{\bar{w}^{2} \frac{1-b}{1-\tau}+\left(\bar{w}_{i}+\frac{\bar{w}}{1-\tau}\right)\left(\bar{w}_{i}-\bar{w}+t_{i}\right)\right\} \\
& S_{f}=1-S_{i} .
\end{aligned}
$$

The goal is to find the expression for the budget restriction of the public sector. Because both public revenue and spending on the means testing program depend on the distribution of wages in the formal sector, one must first find the expression for the latter. Its corresponding cumulative density function is:

$$
F\left(w_{f}\right)= \begin{cases}\frac{1}{S_{f}}\left\{\frac{w_{f}}{2}\left[w_{f}(1-\tau)(1-b)+2\left(b \bar{w}-t_{i}\right)\right]\right\} & \text { if } w_{f} \geq 0 \text { and } w_{f}<\frac{\bar{w}}{1-\tau} \\ \frac{1}{S_{f}}\left\{\phi_{1}+\frac{1}{2}\left(w_{f}-\frac{\bar{w}}{1-\tau}\right)\left[w(2-\tau)-2 t_{i}\right]\right\} & \text { if } w_{f} \geq \frac{\bar{w}}{1-\tau} \text { and } w_{f}<\frac{\overline{w_{i}}}{1-\tau}+t_{i}, \\ \frac{1}{S_{f}}\left\{\phi_{2}+\frac{w_{f}}{\bar{w}_{f}}\right\} & \text { if } w_{f} \geq \frac{\overline{w_{i}}}{1-\tau}+t_{i} \text { and } w_{f} \leq \overline{w_{f}}\end{cases}
$$

where

$$
\begin{aligned}
\phi_{1} & =\frac{\bar{w}}{2(1-\tau)}\left[\bar{w}(1-b)+2\left(b \bar{w}-t_{i}\right)\right] \\
\phi_{2} & =\phi_{1}+\frac{1}{2}\left(\frac{\bar{w}_{i}-\bar{w}}{1-\tau}+t_{i}\right)\left[\left(\frac{\bar{w}_{i}}{1-\tau}+t_{i}\right)(2-\tau)-2 t_{i}\right] .
\end{aligned}
$$

We are now ready to write the budget restriction of the public sector, starting with the expression for public revenue, bearing in mind that only the formal sector is taxed: 


$$
\begin{aligned}
R= & \frac{1}{\bar{w}_{i} \cdot \bar{w}_{f}}\left\{\int_{0}^{\frac{\bar{w}}{1-\tau}} \tau w_{f}\left[w_{f}(1-\tau)(1-b)+b \bar{w}-t_{i}\right] \mathrm{d} w_{f}\right. \\
& +\int_{\frac{\bar{w}}{1-\tau}}^{\frac{\bar{w}_{i}}{1-\tau}+t_{i}} \tau w_{f}\left[2 w_{f}(2-\tau)-2 t_{i}-(2-\tau) \frac{\bar{w}}{1-\tau}\right] \mathrm{d} w_{f} \\
& \left.+\tau \frac{1}{2} \bar{w}_{i}\left[\bar{w}_{f}^{2}-\left(\frac{\bar{w}_{i}}{1-\tau}-t_{i}\right)^{2}\right]\right\} .
\end{aligned}
$$

Finally, the spending side of the budget restriction is as follows:

$$
S=\frac{1}{\bar{w}_{i} \cdot \bar{w}_{f}} \int_{0}^{\frac{\bar{w}}{1-\tau}}\left[\bar{w}-(1-\tau) w_{f}\right] b\left[w_{f}(1-\tau)(1-b)+b \bar{w}-t_{i}\right] \mathrm{d} w_{f}+S_{i} t_{i} .
$$

There are two factors to be discussed in this setting. The first is the effect of taxation. From the expression of $S_{i}$, one can see that informality rises with $\tau$. This is because workers are prone to choose the informal sector where they avoid taxation. However, this narrows the tax base. Moreover, workers who are switching between sectors at the margin are wealthier as the tax rate increases, and taxation is also less progressive as a result. The endogenous limitations to tax collection contrast with those discussed in Hanna and Olken (2018), whose setup emphasizes that a high minimum non-taxable income prevents tax collection from middle-income workers, but in which tax collection is nevertheless pro-poor.

The second factor is the effect of transfers on informal workers in this context. Given a tax rate, increases in transfers to informal workers both further narrow the tax base and increase the number of non-poor informal workers. As a result, transfers to informal workers negatively affect both sides of the government budget constraint: Revenues are reduced and spending is made less efficient. This contrasts with the effect of transfers to formal workers, which underpin the size of the formal sector and public revenues. In addition, the change in formality choice of workers due to taxation generates intricate efficiency effect. This is a factor to be taken into account in programs that intend to widen the tax base, starting from one of relatively high level of minimum untaxed income discussed in Hanna and Olken (2018).

Figure 14 schematically shows the differences between the case in which public revenue is given and the case with taxation. The blue dashed line shows the frontier between formal and informal workers under taxation, while the red line shows the same frontier absent taxation. One can see that the blue line is to the left of the red line, indicating that there is more informality. Moreover, the gap between the blue and red lines widens to the right, indicating that even well-off workers choose the informal sector in order to avoid being subject to taxes, implying less progressive taxation. Finally, because more poor workers are now in the informal sector, they are not eligible for means-tested transfers, which are more pro-poor than general transfers to informal workers. As a result, spending is targeted less effectively. 


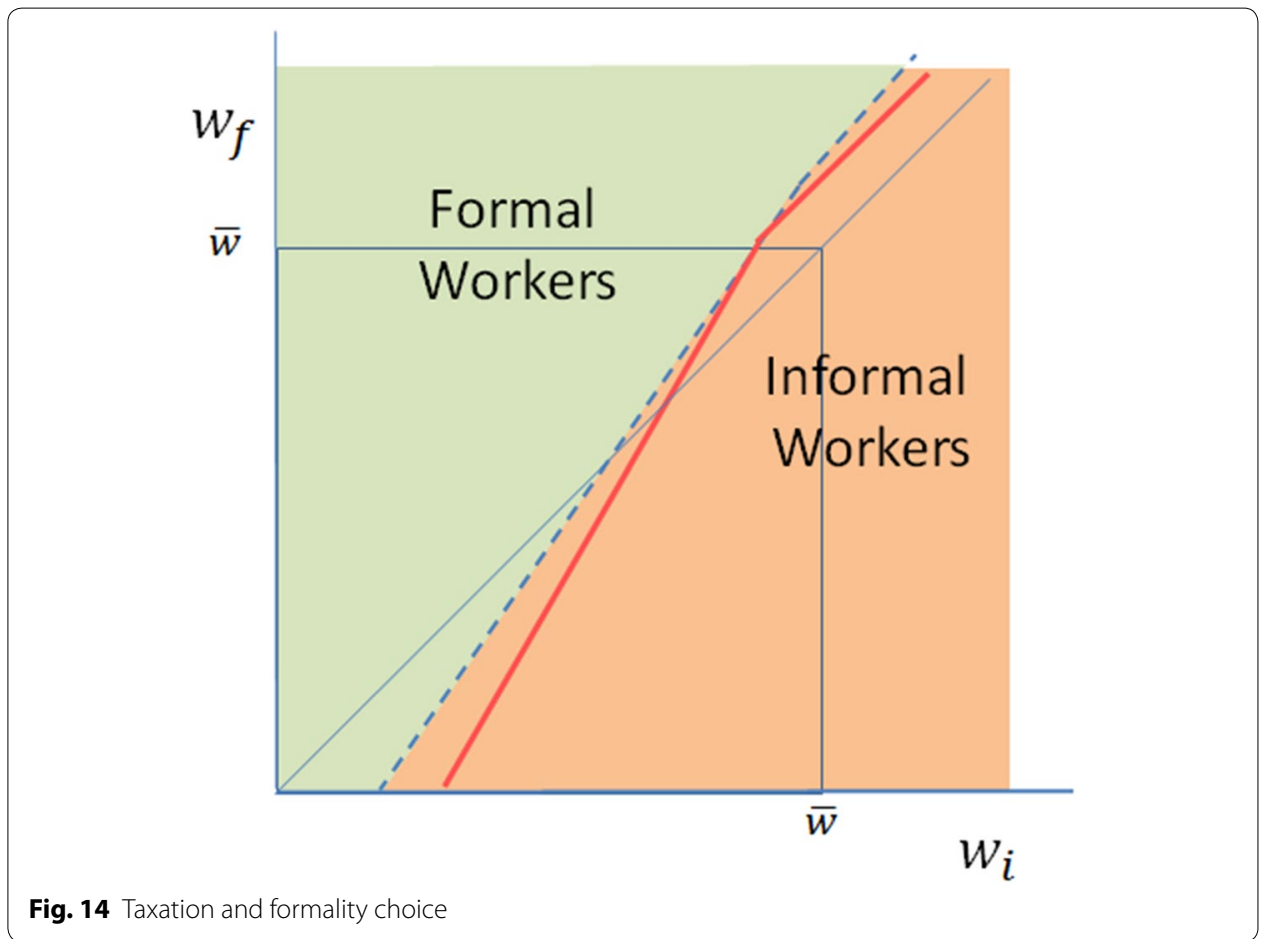

\subsubsection{Proxy means testing programs and taxation}

This section discusses targeting by proxy means testing in the context of taxation. First to be discussed is the case where income support is provided through proxy means testing alone. Relative to the case where the revenue was given, more workers choose the informal sector to avoid taxation, reducing funding available for incomesupport programs. The first effect of taxation is therefore to reduce the overall program size. Additionally, the size of the program also affects how transfers are allocated to characteristics. The lower budget will affect mainly those who are poor but not the poorest of all groups. Figure 15 shows the case of two groups of characteristics, $x^{\prime}$ and $x^{\prime \prime}$, where both groups are poor but the former is poorer. The toll of the diminished revenue will mainly affect group $x^{\prime \prime}$, while it will have a smaller effect on group $x^{\prime}$.

Next to be considered is the case in which formal workers are targeted by means testing and informal workers by proxy means testing. The introduction of taxation in this case implies that the benefit of joining the informal sector for workers is twofold. The first benefit is that of avoiding taxation. The second is the possibility of receiving transfers assigned by proxy means testing. However, from the point of view of the policymaker, the first of these is a cost, and the second will also have an opportunity cost if the beneficiary is not poor. For policymakers, introducing taxation implies that the costs of transfers rise, but they do so more steeply for inclusion errors than exclusion errors. As was the case previously, policymakers will be inclined to implement smaller programs, given the higher cost of redistribution. 


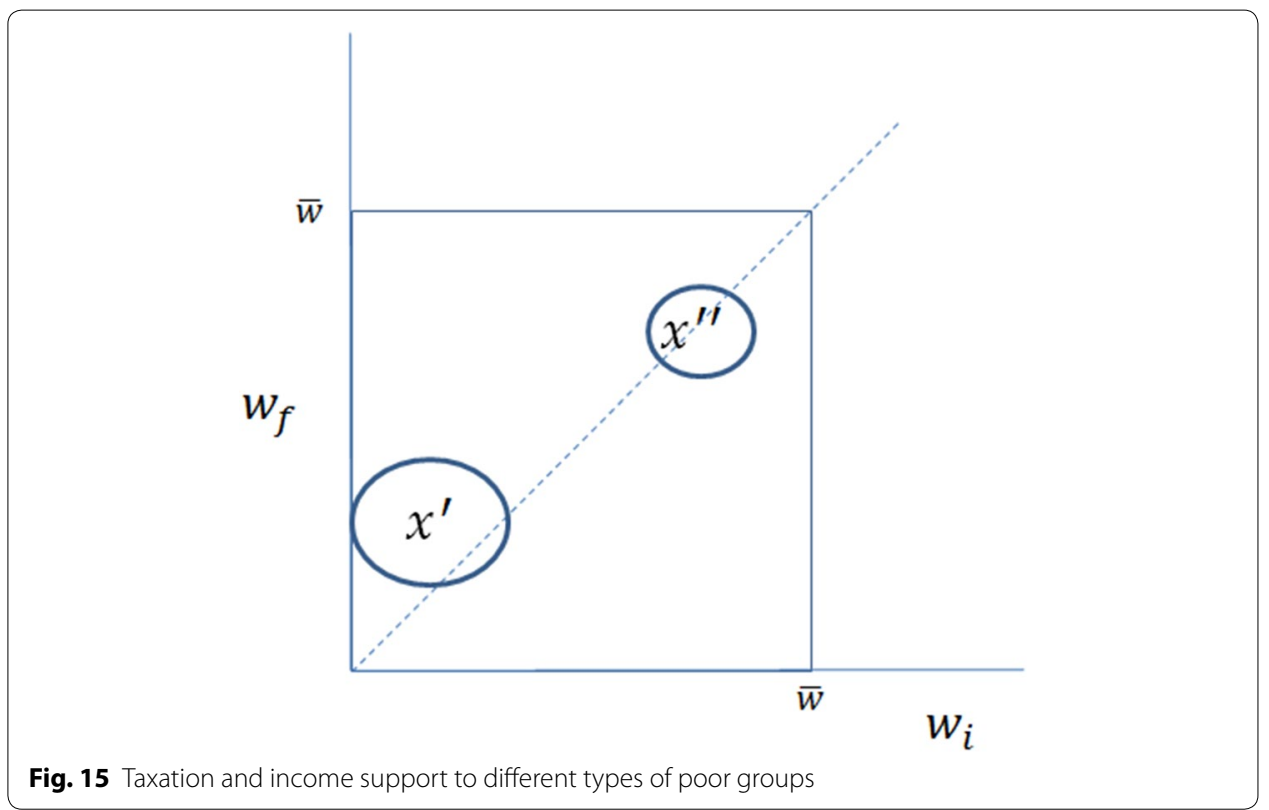

\subsubsection{Program comparison and discussion}

Having laid out the basic features of each program, the next section compares those programs. Of the several arrangements discussed, it was found that the means testing program allows for a pro-poor transfer design but channels workers away from productive jobs in the informal sector, which partly offsets the impact of the transfers. Transfers in the proxy means testing program do not generate distortions, but the pro-poor character of the system of transfers is constrained by the existing relation between poverty and observable characteristics.

The extent to which a proxy means testing mechanism is pro-poor is a question that is at first empirical. The evidence presented previously indicated that classification errors were rather frequent, and this should tilt the balance in favor of means testing programs. However, in practice poor families often work in the informal sector, and this motivates policymakers to promote income support outside the formal sector. The model here indicates that the most general effect of income support to informal workers is an increase in the size of this sector. The effectiveness of these complementary programs in reducing poverty depends on the relation between informality and poverty if support is conditional on informality or, once again, between the strength of the correlation of the observable characteristics available and poverty if support is assigned by means of a proxy means testing design.

Additionally, workers tend to switch to the informal sector as a way to avoid taxation, and governments then require higher tax rates to achieve a desired revenue level compared to a case without an informal sector. Unlike the discussion presented by Hanna and Olken (2018), the difficulty of phasing out a universal basic income program in this model does not come from a high non-taxable minimum income, but rather as a result of endogenous choice from workers. 
If transfers are made to informal workers, more people are encouraged to choose the informal sector to qualify for the subsidy. Unless the relation between informality and poverty is extremely close, the level of filtration is large and the income received by the poor is diluted in the mass of informal workers. This is a general feature of expanding the base of eligibility for social programs (Hanna and Olken 2018), with an additional distortion generated by the switch in sector. A similar logic applies to proxy means testing transfers: Filtration implies that the cost of inclusion errors rises sharply, and policymakers would be more tolerant of exclusion errors. As a consequence, the redistributive capacity of the government is more constrained in these circumstances.

\section{Conclusions}

From a long-term perspective, Latin America and the Caribbean have benefited from a substantial decrease in the incidence and depth of poverty. However, when compared to other developing regions, LAC has performed in line with its peers and experienced declines in poverty that are far from extraordinary. The main driver behind this fall in poverty has been economic growth-not because reducing inequality is ineffective but rather because it has not been consistently achieved over the period studied. Still, growth is a channel that operates over the long run, and even when it facilitates improving the living standards of many poor people, spillovers to all are not straightforward. For those of whom improvements are elusive, poverty alleviation in the form of incomesupport programs is necessary.

To assess the effectiveness of income-support programs, this paper built a formal model where workers have working opportunities in both the formal and informal sectors, and examined how means testing programs compare to proxy means testing programs. Because means testing programs are more flexible, a pro-poor design is possible, while the pro-poor character of proxy means testing programs is constrained by the relation between observable characteristics and poverty. However, implementation of means testing programs may be problematic if there is underreporting of income at the intensive margin. Meanwhile, the relation between observable characteristics and poverty is not stable over time, which may weaken the targeting efficiency of proxy means testing programs, and these programs are more distortive in a context where raising revenue for redistribution is necessary.

While proxy means testing is the industry standard for developing economies, means testing is much more widespread in the developed world. The ability of a government to observe incomes is a leading factor in determining the targeting design. It is possible that if developing countries continue on the growth path that they have experienced the last several decades, they will eventually acquire the capabilities that are necessary for means testing programs. If this is so, the transition from proxy means testing to means testing will be a natural one. 
On the other hand, a more skeptical view would suspect that the existing structure of transfer programs affects the aforementioned process in some way, possibly slowing it. Additionally, one would also wonder whether a safety net designed for informal workers will hold them back in informality, and whether this retention has implications for human capital acquisition and long-run growth.

A central feature to this dichotomy is the effectiveness of policies to affect the formality decisions of workers. In particular, are subsidies and tax incentives sufficiently large to pull a significant amount of the labor force into the formal sector? Moreover, will complementary reforms be necessary to ease the burden of formality on firms, and should special consideration be given to smaller firms, or those that are typically believed to have complying with these requirements? Finally, there is the question of whether proxy means targeting and means testing programs will have to coexist during the hypothetical transition, and, if so, what this coexistence should be like.

Acknowledgements

We would like to thank an anonymous referee for reviewing this paper.

Authors' contributions

The authors contributed equally to the writing and reviewing of this paper. All authors read and approved the final manuscript.

Funding

Generous funding for this Project was provided by the Inter-American Development Bank.

Availability of data and materials

Data used in this paper are available online at http://iresearch.worldbank.org/PovcalNet/povOnDemand.aspx.

Competing interests

The authors declare that they have no competing interests.

Author details

${ }^{1}$ Department of Economics, University of California, Berkeley, Berkeley, USA. ${ }^{2}$ Department of Economics, University of Maryland, College Park, USA. ${ }^{3}$ Department of Economics, Universidad Tocuato di Tella, Buenos Aires, Argentina.

\section{Appendix}

See Tables 9, 10, 11, 12, 13, and 14 . 


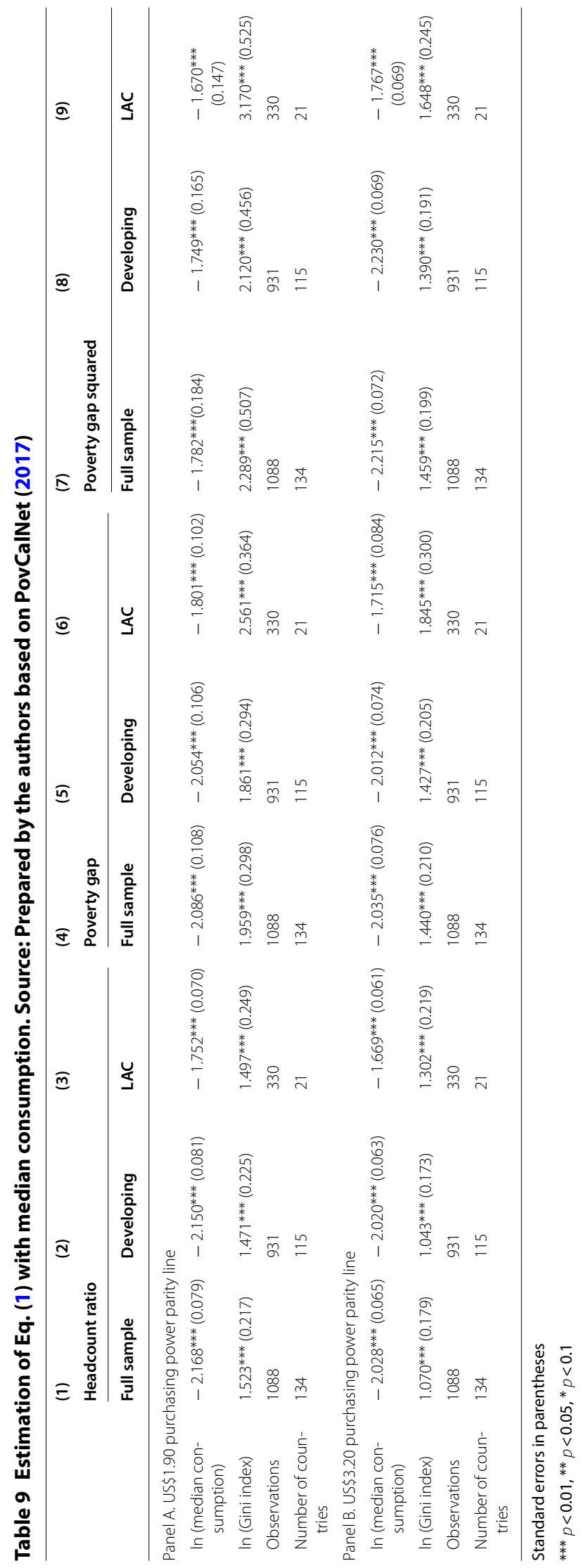


Table 10 Decomposition of changes in the headcount ratio (US\$1.9 purchasing power parity line). Source: Prepared by the authors based on PovCaINet (2017)

\begin{tabular}{|c|c|c|c|c|c|c|c|}
\hline Country & Years in sample & $\log \left(P_{i f} / P_{i 0}\right)$ & $\log \left(M_{i f} / M_{i 0}\right)$ & $\log \left(I_{i f} / I_{i 0}\right)$ & Growth effect & $\begin{array}{l}\text { Inequality } \\
\text { effect }\end{array}$ & Sum \\
\hline Argentina & $1991-2014$ & 0.44 & 0.05 & -0.09 & -0.11 & -0.26 & -0.37 \\
\hline Belize & 1993-1999 & 0.32 & -0.26 & -0.12 & 0.58 & -0.35 & 0.22 \\
\hline Bolivia & 1990-2014 & -0.52 & 0.53 & 0.08 & -1.19 & 0.22 & -0.97 \\
\hline Brazil & $1981-2014$ & -1.89 & 0.92 & -0.12 & -2.08 & -0.34 & -2.42 \\
\hline Chile & $1987-2013$ & -2.22 & 0.73 & -0.11 & -1.64 & -0.31 & -1.95 \\
\hline Colombia & 1992-2014 & -0.36 & 0.38 & 0.04 & -0.86 & 0.11 & -0.75 \\
\hline Costa Rica & 1986-2014 & -2.34 & 1.21 & 0.28 & -2.75 & 0.80 & -1.94 \\
\hline Dom. Rep. & 1986-2013 & -3.10 & 1.13 & -0.08 & -2.55 & -0.23 & -2.78 \\
\hline Ecuador & 1987-2014 & -2.10 & 0.59 & -0.17 & -1.33 & -0.49 & -1.82 \\
\hline El Salvador & 1991-2014 & -1.94 & 0.33 & -0.25 & -0.75 & -0.73 & -1.48 \\
\hline Guatemala & 1986-2014 & -1.99 & 0.78 & -0.24 & -1.76 & -0.70 & -2.46 \\
\hline Haiti & $2001-2012$ & -0.03 & 0.05 & 0.02 & -0.12 & 0.06 & -0.05 \\
\hline Honduras & 1989-2014 & -1.18 & 0.31 & -0.23 & -0.71 & -0.65 & -1.36 \\
\hline Jamaica & 1988-2004 & -1.45 & 0.45 & 0.05 & -1.02 & 0.15 & -0.87 \\
\hline Mexico & 1984-2014 & -0.96 & 0.12 & -0.02 & -0.27 & -0.04 & -0.32 \\
\hline Nicaragua & 1993-2014 & -1.56 & 0.36 & -0.13 & -0.83 & -0.38 & -1.21 \\
\hline Panama & 1989-2014 & -1.84 & 0.78 & -0.15 & -1.77 & -0.43 & -2.20 \\
\hline Paraguay & 1990-2014 & 0.84 & 0.30 & 0.24 & -0.68 & 0.68 & 0.00 \\
\hline Peru & 1985-2014 & -1.96 & 0.75 & -0.10 & -1.69 & -0.28 & -1.97 \\
\hline Uruguay & 1989-2014 & -0.43 & 0.18 & -0.02 & -0.40 & -0.05 & -0.45 \\
\hline Venezuela & 1989-2006 & 0.17 & 0.04 & 0.04 & -0.09 & 0.10 & 0.01 \\
\hline
\end{tabular}

Table 11 Decomposition of changes in the poverty gap (US\$1.9 purchasing power parity line). Source: Prepared by the authors based on PovCalNet (2017)

\begin{tabular}{|c|c|c|c|c|c|c|c|}
\hline Country & Years in sample & $\log \left(P_{i f} / P_{i 0}\right)$ & $\log \left(M_{i f} / M_{i 0}\right)$ & $\log \left(I_{i f} / l_{i 0}\right)$ & Growth effect & $\begin{array}{l}\text { Inequality } \\
\text { effect }\end{array}$ & Sum \\
\hline Argentina & $1991-2014$ & 0.37 & 0.05 & -0.09 & -0.10 & -0.30 & -0.40 \\
\hline Belize & 1993-1999 & 0.21 & -0.26 & -0.12 & 0.56 & -0.40 & 0.16 \\
\hline Bolivia & 1990-2014 & 0.31 & 0.53 & 0.08 & -1.15 & 0.25 & -0.90 \\
\hline Brazil & $1981-2014$ & -1.75 & 0.92 & -0.12 & -2.01 & -0.38 & -2.39 \\
\hline Chile & 1987-2013 & -1.92 & 0.73 & -0.11 & -1.59 & -0.35 & -1.94 \\
\hline Colombia & 1992-2014 & -0.66 & 0.38 & 0.04 & -0.83 & 0.13 & -0.70 \\
\hline Costa Rica & 1986-2014 & -2.56 & 1.21 & 0.28 & -2.65 & 0.91 & -1.75 \\
\hline Dom. Rep. & 1986-2013 & -3.87 & 1.13 & -0.08 & -2.46 & -0.26 & -2.72 \\
\hline Ecuador & $1987-2014$ & -2.44 & 0.59 & -0.17 & -1.28 & -0.56 & -1.84 \\
\hline El Salvador & $1991-2014$ & -2.78 & 0.33 & -0.25 & -0.73 & -0.83 & -1.56 \\
\hline Guatemala & 1986-2014 & -2.72 & 0.78 & -0.24 & -1.70 & -0.80 & -2.49 \\
\hline Haiti & $2001-2012$ & 0.03 & 0.05 & 0.02 & -0.11 & 0.07 & -0.04 \\
\hline Honduras & 1989-2014 & -1.53 & 0.31 & -0.23 & -0.68 & -0.73 & -1.42 \\
\hline Jamaica & 1988-2004 & -1.67 & 0.45 & 0.05 & -0.99 & 0.17 & -0.82 \\
\hline Mexico & 1984-2014 & -1.03 & 0.12 & -0.02 & -0.26 & -0.05 & -0.31 \\
\hline Nicaragua & 1993-2014 & -1.99 & 0.36 & -0.13 & -0.80 & -0.43 & -1.23 \\
\hline Panama & 1989-2014 & -2.60 & 0.78 & -0.15 & -1.71 & -0.49 & -2.20 \\
\hline Paraguay & 1990-2014 & 1.04 & 0.30 & 0.24 & -0.65 & 0.77 & 0.11 \\
\hline Peru & $1985-2014$ & -2.37 & 0.75 & -0.10 & -1.64 & -0.32 & -1.95 \\
\hline Uruguay & 1989-2014 & -0.51 & 0.18 & -0.02 & -0.38 & -0.06 & -0.44 \\
\hline Venezuela & 1989-2006 & 0.20 & 0.04 & 0.04 & -0.09 & 0.12 & 0.03 \\
\hline
\end{tabular}


Table 12 Decomposition of changes in the poverty gap (US\$3.2 purchasing power parity line). Source: Prepared by the authors based on PovCalNet (2017)

\begin{tabular}{|c|c|c|c|c|c|c|c|}
\hline Country & Years in sample & $\log \left(P_{i f} / P_{i 0}\right)$ & $\log \left(M_{i f} / M_{i 0}\right)$ & $\log \left(I_{i f} / I_{i 0}\right)$ & Growth effect & $\begin{array}{l}\text { Inequality } \\
\text { effect }\end{array}$ & Sum \\
\hline Argentina & 1991-2014 & 0.37 & 0.05 & -0.09 & -0.10 & -0.25 & -0.35 \\
\hline Belize & 1993-1999 & 0.21 & -0.26 & -0.12 & 0.54 & -0.33 & 0.21 \\
\hline Bolivia & 1990-2014 & -0.01 & 0.53 & 0.08 & -1.11 & 0.21 & -0.90 \\
\hline Brazil & $1981-2014$ & -1.77 & 0.92 & -0.12 & -1.94 & -0.32 & -2.26 \\
\hline Chile & 1987-2013 & -2.01 & 0.73 & -0.11 & -1.54 & -0.29 & -1.83 \\
\hline Colombia & 1992-2014 & -0.60 & 0.38 & 0.04 & -0.80 & 0.11 & -0.70 \\
\hline Costa Rica & 1986-2014 & -2.24 & 1.21 & 0.28 & -2.57 & 0.76 & -1.81 \\
\hline Dom. Rep. & 1986-2013 & -3.12 & 1.13 & -0.08 & -2.38 & -0.22 & -2.60 \\
\hline Ecuador & 1987-2014 & -2.01 & 0.59 & -0.17 & -1.24 & -0.46 & -1.71 \\
\hline El Salvador & $1991-2014$ & -2.20 & 0.33 & -0.25 & -0.70 & -0.69 & -1.39 \\
\hline Guatemala & 1986-2014 & -2.10 & 0.78 & -0.24 & -1.64 & -0.66 & -2.30 \\
\hline Haiti & $2001-2012$ & -1.05 & 0.05 & 0.02 & -0.11 & 0.06 & -0.05 \\
\hline Honduras & 1989-2014 & -1.07 & 0.31 & -0.23 & -0.66 & -0.61 & -1.27 \\
\hline Jamaica & 1988-2004 & -1.37 & 0.45 & 0.05 & -0.95 & 0.14 & -0.81 \\
\hline Mexico & 1984-2014 & -0.90 & 0.12 & -0.02 & -0.26 & -0.04 & -0.30 \\
\hline Nicaragua & 1993-2014 & -1.96 & 0.36 & -0.13 & -0.77 & -0.36 & -1.13 \\
\hline Panama & 1989-2014 & -2.31 & 0.78 & -0.15 & -1.65 & -0.41 & -2.06 \\
\hline Paraguay & 1990-2014 & 0.77 & 0.30 & 0.24 & -0.63 & 0.64 & 0.01 \\
\hline Peru & 1985-2014 & -1.91 & 0.75 & -0.10 & -1.58 & -0.27 & -1.85 \\
\hline Uruguay & 1989-2014 & -0.49 & 0.18 & -0.02 & -0.37 & -0.05 & -0.42 \\
\hline Venezuela & 1989-2006 & 0.19 & 0.04 & 0.04 & -0.09 & 0.10 & 0.01 \\
\hline
\end{tabular}

Table 13 Decomposition of changes in the poverty gap squared (US\$1.9 purchasing power parity line). Source: Prepared by the authors based on PovCalNet (2017)

\begin{tabular}{|c|c|c|c|c|c|c|c|}
\hline Country & Years in sample & $\log \left(P_{i f} / P_{i 0}\right)$ & $\log \left(M_{i f} / M_{i 0}\right)$ & $\log \left(I_{i f} / l_{i 0}\right)$ & Growth effect & $\begin{array}{l}\text { Inequality } \\
\text { effect }\end{array}$ & Sum \\
\hline Argentina & $1991-2014$ & 0.35 & 0.05 & -0.09 & -0.09 & -0.31 & -0.40 \\
\hline Belize & 1993-1999 & 0.18 & -0.26 & -0.12 & 0.48 & -0.42 & 0.06 \\
\hline Bolivia & 1990-2014 & 1.73 & 0.53 & 0.08 & -0.99 & 0.26 & -0.73 \\
\hline Brazil & 1981-2014 & -1.59 & 0.92 & -0.12 & -1.73 & -0.40 & -2.13 \\
\hline Chile & 1987-2013 & -1.67 & 0.73 & -0.11 & -1.37 & -0.37 & -1.74 \\
\hline Colombia & 1992-2014 & -0.94 & 0.38 & 0.04 & -0.72 & 0.13 & -0.58 \\
\hline Costa Rica & 1986-2014 & -2.04 & 1.21 & 0.28 & -2.29 & 0.95 & -1.34 \\
\hline Dom. Rep. & $1986-2013$ & -3.85 & 1.13 & -0.08 & -2.12 & -0.27 & -2.39 \\
\hline Ecuador & $1987-2014$ & -1.95 & 0.59 & -0.17 & -1.11 & -0.58 & -1.69 \\
\hline El Salvador & $1991-2014$ & -3.46 & 0.33 & -0.25 & -0.63 & -0.86 & -1.49 \\
\hline Guatemala & 1986-2014 & -2.58 & 0.78 & -0.24 & -1.46 & -0.83 & -2.29 \\
\hline Haiti & $2001-2012$ & 0.07 & 0.05 & 0.02 & -0.10 & 0.07 & -0.02 \\
\hline Honduras & 1989-2014 & -1.09 & 0.31 & -0.23 & -0.59 & -0.77 & -1.36 \\
\hline Jamaica & 1988-2004 & -2.03 & 0.45 & 0.05 & -0.85 & 0.18 & -0.67 \\
\hline Mexico & 1984-2014 & -1.11 & 0.12 & -0.02 & -0.23 & -0.05 & -0.28 \\
\hline Nicaragua & $1993-2014$ & -1.64 & 0.36 & -0.13 & -0.69 & -0.45 & -1.14 \\
\hline Panama & 1989-2014 & -3.15 & 0.78 & -0.15 & -1.47 & -0.51 & -1.98 \\
\hline Paraguay & 1990-2014 & 0.92 & 0.30 & 0.24 & -0.56 & 0.80 & 0.23 \\
\hline Peru & 1985-2014 & -2.05 & 0.75 & -0.10 & -1.41 & -0.33 & -1.74 \\
\hline Uruguay & 1989-2014 & -0.47 & 0.18 & -0.02 & -0.33 & -0.06 & -0.39 \\
\hline Venezuela & 1989-2006 & 0.21 & 0.04 & 0.04 & -0.08 & 0.12 & 0.04 \\
\hline
\end{tabular}


Table 14 Decomposition of changes in the poverty gap squared (US\$3.2 purchasing power parity line). Source: Prepared by the authors based on PovCalNet (2017)

\begin{tabular}{|c|c|c|c|c|c|c|c|}
\hline Country & Years in sample & $\log \left(P_{i f} / P_{i 0}\right)$ & $\log \left(M_{i f} / M_{i 0}\right)$ & $\log \left(I_{i f} I_{i 0}\right)$ & Growth effect & $\begin{array}{l}\text { Inequality } \\
\text { effect }\end{array}$ & Sum \\
\hline Argentina & $1991-2014$ & 0.41 & 0.05 & -0.09 & -0.11 & -0.26 & -0.37 \\
\hline Belize & 1993-1999 & 0.17 & -0.26 & -0.12 & 0.59 & -0.35 & 0.24 \\
\hline Bolivia & 1990-2014 & -0.29 & 0.53 & 0.08 & -1.21 & 0.22 & -0.99 \\
\hline Brazil & $1981-2014$ & -1.97 & 0.92 & -0.12 & -2.11 & -0.34 & -2.45 \\
\hline Chile & 1987-2013 & -2.33 & 0.73 & -0.11 & -1.67 & -0.31 & -1.98 \\
\hline Colombia & 1992-2014 & -0.06 & 0.38 & 0.04 & -0.87 & 0.11 & -0.76 \\
\hline Costa Rica & 1986-2014 & -2.56 & 1.21 & 0.28 & -2.79 & 0.79 & -2.00 \\
\hline Dom. Rep. & 1986-2013 & -2.99 & 1.13 & -0.08 & -2.59 & -0.23 & -2.81 \\
\hline Ecuador & 1987-2014 & -2.20 & 0.59 & -0.17 & -1.35 & -0.49 & -1.84 \\
\hline El Salvador & 1991-2014 & -1.82 & 0.33 & -0.25 & -0.76 & -0.72 & -1.49 \\
\hline Guatemala & 1986-2014 & -2.06 & 0.78 & -0.24 & -1.78 & -0.70 & -2.48 \\
\hline Haiti & $2001-2012$ & -1.05 & 0.05 & 0.02 & -0.12 & 0.06 & -0.06 \\
\hline Honduras & 1989-2014 & -1.12 & 0.31 & -0.23 & -0.72 & -0.64 & -1.36 \\
\hline Jamaica & 1988-2004 & -1.21 & 0.45 & 0.05 & -1.04 & 0.15 & -0.89 \\
\hline Mexico & 1984-2014 & -0.85 & 0.12 & -0.02 & -0.28 & -0.04 & -0.32 \\
\hline Nicaragua & 1993-2014 & -1.88 & 0.36 & -0.13 & -0.84 & -0.38 & -1.21 \\
\hline Panama & 1989-2014 & -1.67 & 0.78 & -0.15 & -1.79 & -0.43 & -2.22 \\
\hline Paraguay & $1990-2014$ & 0.83 & 0.30 & 0.24 & -0.69 & 0.67 & -0.02 \\
\hline Peru & $1985-2014$ & -1.88 & 0.75 & -0.10 & -1.72 & -0.28 & -2.00 \\
\hline Uruguay & 1989-2014 & -0.63 & 0.18 & -0.02 & -0.40 & -0.05 & -0.46 \\
\hline Venezuela & 1989-2006 & 0.14 & 0.04 & 0.04 & -0.10 & 0.10 & 0.01 \\
\hline
\end{tabular}

Received: 8 September 2019 Accepted: 21 October 2019

Published online: 14 November 2019

References

Alatas V, Banerjee A, Hanna R, Olken B, Tobias J (2012) Targeting the poor: evidence from a field experiment in Indonesia. Am Econ Rev 102(4):1206-1240

Barr N (1998) The economics of the welfare state. Stanford University Press, Stanford

Besley T, Coate S (1992) Workfare versus welfare: incentive arguments for work requirements in poverty-alleviation programs. Am Econ Rev 82(1):249-261

Bourguignon $\mathrm{F}$ (2003) The growth elasticity of poverty reduction: explaining heterogeneity across countries and time periods. In: Eicher T, Turnovsky S (eds) Inequality and growth, theory and policy implications. The MIT Press, Cambridge

De Wachter S, Galiani S (2006) Optimal income support targeting. Int Tax Public Financ 13(6):661-684

Foster J, Greer J, Thorbecke E (1984) A class of decomposable poverty measures. Econometrica 52:761-766

Galiani S, Weinschelbaum F (2012) Modeling informality formally: households and firms. Econ Inq 50:821-838

Gasparini L, Sosa Escudero W, Cicowiez M (2014) Pobreza y desigualdad en América Latina: conceptos, herramientas y aplicaciones. CEDLAS Working Paper 0171. Universidad Nacional de La Plata

Hanna R, Olken BA (2018) Universal basic incomes versus targeted transfers: anti-poverty programs in developing countries. J Econ Perspect 32(4):201-206

Kraay A (2006) When is growth pro-poor? Evidence from a panel of countries. J Dev Econ 80(1):198-227

Londoño JL, Székely M (2000) Persistent poverty and excess inequality: Latin America, 1970-1995. J Appl Econ 3(1):93-134

PovCalNet (2017) Select countries aggregation. World Bank, Washington, DC. http://iresearch.worldbank.org/PovcalNet/ povOnDemand.aspx. Accessed 25 Oct 2017

Ravallion M (1997) Can high-inequality developing countries escape absolute poverty? Econ Lett 56(1):51-57

Ravallion M, Chen S (1997) What can new survey data tell us about recent changes in distribution and poverty? World Bank Econ Rev 11(2):357-382

Ravallion M, Chen S, Sangraula P (2009) Dollar a day revisited. World Bank Econ Rev 23(2):163-184

Schneider F, Buehn A, Montenegro C (2010) New estimates for the shadow economies all over the world. Int Econ J 24(4):443-461 
SEDLAC (2016) Socio-economic database for Latin America and the Caribbean (CEDLAS). La Plata. http://www.cedla s.econo.unlp.edu.ar/wp/en/estadisticas/sedlac/. Accessed 10 Jan 2016

Sen A (1976) Poverty: an ordinal approach to measurement. Econometrica 4(2):219-231

Stampini M, Tornarolli L (2012). The growth of conditional cash transfers in Latin America and the Caribbean: did they go too far? IZA Policy Paper No. 49. Institute for the Study of Labor, Bonn

\section{Publisher's Note}

Springer Nature remains neutral with regard to jurisdictional claims in published maps and institutional affiliations.

Submit your manuscript to a SpringerOpen ${ }^{\circ}$ journal and benefit from:

- Convenient online submission

- Rigorous peer review

- Open access: articles freely available online

- High visibility within the field

Retaining the copyright to your article

Submit your next manuscript at $\boldsymbol{\Delta}$ springeropen.com 